\title{
Size and Synchronization of Auditory Cortex Promotes Musical, Literacy, and Attentional Skills in Children
}

\author{
(1) Annemarie Seither-Preisler, ${ }^{1,2}$ Richard Parncutt, ${ }^{2}$ and Peter Schneider ${ }^{3}$ \\ ${ }^{1}$ Cognitive Psychology and Neuroscience Section, Institute of Psychology and ${ }^{2}$ Centre for Systematic Musicology, University of Graz, A-8010 Graz, Austria, \\ and ${ }^{3}$ Department of Neuroradiology and Department of Neurology, Section of Biomagnetism, University of Heidelberg Medical School, D-69120 \\ Heidelberg, Germany
}

\begin{abstract}
Playing a musical instrument is associated with numerous neural processes that continuously modify the human brain and may facilitate characteristic auditory skills. In a longitudinal study, we investigated the auditory and neural plasticity of musical learning in 111 young children (aged 7-9 y) as a function of the intensity of instrumental practice and musical aptitude. Because of the frequent co-occurrence of central auditory processing disorders and attentional deficits, we also tested 21 children with attention deficit (hyperactivity) disorder $[\mathrm{AD}(\mathrm{H}) \mathrm{D}]$. Magnetic resonance imaging and magnetoencephalography revealed enlarged Heschl's gyri and enhanced right-left hemispheric synchronization of the primary evoked response (P1) to harmonic complex sounds in children who spent more time practicing a musical instrument. The anatomical characteristics were positively correlated with frequency discrimination, reading, and spelling skills. Conversely, $\mathrm{AD}(\mathrm{H}) \mathrm{D}$ children showed reduced volumes of Heschl's gyri and enhanced volumes of the plana temporalia that were associated with a distinct bilateral P1 asynchrony. This may indicate a risk for central auditory processing disorders that are often associated with attentional and literacy problems. The longitudinal comparisons revealed a very high stability of auditory cortex morphology and gray matter volumes, suggesting that the combined anatomical and functional parameters are neural markers of musicality and attention deficits. Educational and clinical implications are considered.
\end{abstract}

Key words: auditory cortex; auditory evoked responses; magnetencephalography; morphometry; musical aptitude; musical learning; ADHD

\section{Introduction}

The brains of musicians are an excellent model for investigating the complexity and multimodality of auditory processing, the variability of individual hearing abilities, and the influence of dispositional and developmental factors on the maturation of neural and cognitive functions. Musical training improves discrimination of pitch (Micheyl et al., 2006; Seither-Preisler et al., 2007), timbre (Pantev et al., 2001), chords (Koelsch et al., 1999), rhythm (Rammsayer and Altenmueller, 2006), and melodies (Trainor et al., 1999). Moreover, musicians typically have highly developed auditory cortices (ACs; Schlaug et al., 1995; Schneider et al., 2002) with stronger functional activation (Besson and Faita, 1995; Pantev et al., 1998; Koelsch et al., 2002, 2005; Tervaniemi et al., 2006; White-Schwoch et al., 2013), en-

Received Dec. 19, 2013; revised June 27, 2014; accepted June 29, 2014.

Author contributions: A.S.-P. and P.S. designed research; A.S.-P. and P.S. performed research; A.S.-P. and P.S. analyzed data; A.S.-P., R.P., and P.S. wrote the paper.

This work was supported by German Federal Ministry of Education and Research (BMBF) project 01KJ0809/10 ("AMsel: Audio- and Neuroplasticity of Musical Learning"). We thank M. Bendszus and A. Rupp for providing the 3D-MRI and MEG in Heidelberg, A. Seitz and M. Wengenroth for preprocessing and diagnosing the MRI scans, S. Seither for technical support, S. Hoellmueller for conducting the psychological tests, and U. Goswami/M. Huss for providing the psychoacoustic Dinosaur Test.

The authors declare no competing financial interests.

Correspondence should be addressed to Annemarie Seither-Preisler, Institute of Psychology, University of Graz, Universitaetsplatz 2, A-8010 Graz, Austria. E-mail: annemarie.seither-preisler@uni-graz.at.

DOI:10.1523/JNEUROSCI.5315-13.2014

Copyright $\odot 2014$ the authors $\quad 0270-6474 / 14 / 3410937-13 \$ 15.00 / 0$ hanced top-down processing of auditory information (Zatorre and McGill, 2005; Zatorre et al., 2007; Scheich et al., 2011), and more efficient preattentive functions, particularly in response to the sounds of the trained instrument (Fujioka et al., 2006; Shahin et al., 2008; Chobert et al., 2014).

The gross morphology of the AC is associated with perceptual and cognitive skills, such as relative and absolute pitch ability (Schneider et al., 2005; Foster and Zatorre, 2010; Wengenroth et al. 2010, 2014) or speech learning (Golestani et al., 2007; Wong et al., 2008; Hartwigsen et al., 2010). Although there is evidence for a genetic influence on auditory and musical abilities (Oikkonen et al., 2014), it is unclear how a priori dispositions interact with environmental influences and in particular with musical training, which in turn has been shown to positively influence auditory brain functions (Jäncke et al., 2000; Muente et al., 2002; Sluming et al., 2007; Altenmüller, 2008; Chen et al., 2008; Jäncke, 2009; Wan and Schlaug, 2010; Strait and Kraus, 2014). Musically induced advantages have also been demonstrated in long-term studies (Hyde et al., 2009; Moreno et al., 2009; Chobert et al., 2014) and appear to be retained from childhood to adulthood (Skoe and Kraus, 2012).

From a clinical perspective, pathologies, such as stroke (Schneider et al., 2007; Grau-Sanchez et al., 2013), tinnitus (Schneider et al., 2009), Parkinson's disease (Nombela et al., 2013), and Alzheimer's disease (Janata, 2012), and learning disorders, such as dyslexia or attention problems (Kraus and Chan- 
Table 1. Description of participants

\begin{tabular}{|c|c|c|c|c|c|c|c|c|}
\hline \multirow[b]{2}{*}{ Total sample } & \multicolumn{4}{|c|}{$\begin{array}{l}\text { Main group } \\
\text { mean age at MTP1: } 8.6 \text { years } \pm 9 \text { months }\end{array}$} & \multicolumn{4}{|c|}{$\begin{array}{l}A D(H) D \text { group } \\
\text { mean age at MTP1: } 8.9 \text { years } \pm 8 \text { months }\end{array}$} \\
\hline & $\begin{array}{l}n=111 \\
(54 \text { males, } 57 \mathrm{fe}\end{array}$ & & & & $\begin{array}{l}n=21 \\
\text { (all males) }\end{array}$ & & & \\
\hline Longitudinal MRI sample & $\begin{array}{l}n=102 \\
\text { (49 males, } 53 \mathrm{fe}\end{array}$ & & & & $n=21$ & & & \\
\hline Longitudinal MEG sample & $\begin{array}{l}n=102 \\
(51 \text { males, } 51 \mathrm{fe}\end{array}$ & & & & $n=20$ & & & \\
\hline Number of subjects & 38 & 38 & 16 & 19 & 5 & 4 & 2 & 10 \\
\hline $\begin{array}{l}\text { Age in months at MTP1 } \\
\text { (years; months) }\end{array}$ & $\begin{array}{l}104.1 \pm 8.5 \\
\quad(8 ; 8)\end{array}$ & $\begin{array}{l}101.8 \pm 10.7 \\
(8 ; 6)\end{array}$ & $\begin{array}{l}104.4 \pm 8.5 \\
(8 ; 8)\end{array}$ & $\begin{array}{l}97.8 \pm 7.1 \\
(8 ; 2)\end{array}$ & $\begin{array}{c}100.6 \pm 4.7 \\
(8 ; 5)\end{array}$ & $\begin{array}{c}108 \pm 6.9 \\
(9 ; 0)\end{array}$ & $\begin{array}{c}116 \pm 5.6 \\
(9 ; 8)\end{array}$ & $\begin{array}{l}103.9 \pm 8.5 \\
\quad(8 ; 8)\end{array}$ \\
\hline $\begin{array}{l}\text { Musical starting age } \\
\text { (years; months) }\end{array}$ & $\begin{array}{l}85.5 \pm 12.9 \\
(7 ; 2)\end{array}$ & $\begin{array}{l}71.8 \pm 14.7 \\
(6 ; 0)\end{array}$ & $\begin{array}{l}95.3 \pm 8.6 \\
(7 ; 11)\end{array}$ & & $\begin{array}{c}94.6 \pm 4.7 \\
(7 ; 11)\end{array}$ & $\begin{array}{l}90 \pm 18.5 \\
(7 ; 6)\end{array}$ & $\begin{array}{l}92 \pm 5.7 \\
(7 ; 8)\end{array}$ & \\
\hline (Total) $I_{\text {MP }}$ at MTP2 & $4.2 \pm 4.2$ & $8.3 \pm 6.5$ & $1.4 \pm 0.8$ & & $1.6 \pm 0.8$ & $4.5 \pm 4.0$ & $1.5 \pm 0.01$ & \\
\hline
\end{tabular}

Both the main group and the $A D(H) D$ group included children with and without musical experience but in different proportions. The children were musically trained in extracurricular private lessons, the JeKi program offered at school, or both $I_{\text {MPs }}$ are separately listed for the JeKi-related and private training at MTP1 and MTP2. If not stated otherwise in the text, $I_{\text {MP }}$ is the total accumulated practice (JeKi + private) at MTP2. All means and SDs are based on the total sample and not on the slightly reduced samples of the longitudinal MRI and MEG analyses.

drasekaran, 2010; Strait and Kraus, 2014), have been found to benefit from musical training. In AC, sensory bottom-up and attentional top-down processing are closely related to each other (Schadow et al., 2009; Scheich et al., 2011; Bailey, 2012). Hence, it is not surprising that central auditory processing disorders (CAPDs; Cacace and McFarland, 1998) appear in complex comorbidities of attention (Sergeant et al., 2003), language, and literacy problems (Dawes et al., 2009). These may be determined by genetic (Larsson et al., 2006), biochemical (Martel et al., 2009), or anatomical (Sowell et al., 2003) influences and have been ascribed to a delay in cortical maturation (Shaw et al., 2007; Konrad and Eickhoff, 2010). Therefore, the investigation of the young and adolescent brain may be a promising strategy for understanding the neural basis of CAPD and attention deficit (hyperactivity) disorder $[\mathrm{AD}(\mathrm{H}) \mathrm{D}]$. Although in the normal population the prevalence of CAPD is 2-3\% (Chermak and Musiek, 1997), it occurs in $\sim 50 \%$ in subjects with $\mathrm{AD}(\mathrm{H}) \mathrm{D}$ (Riccio et al., 1994, 2005). This raises the question of whether perceptual problems cause attentional deficits or vice versa (Dawes et al., 2009). Although the variety of neurophysiological anomalies in $\mathrm{AD}(\mathrm{H}) \mathrm{D}$ (Sowell et al., 2003) is inconsistent with a purely auditory explanation (Woods et al., 2002), subtle hearing problems appear to be a contributing factor (Chermak et al., 1999; Bailey, 2012). Recent research has revealed that, apart from attentional problems, $\mathrm{AD}(\mathrm{H}) \mathrm{D}$ may involve a core deficit in auditory, visual, and motor timing (Falter and Noreika, 2011; Noreika et al., 2013), with timeframes ranging from milliseconds to minutes or even longer. The most consistent impairments are found in sensorimotor synchronization, duration discrimination, time-interval reproduction, and delay discounting. Moreover, there is growing evidence for an association between perceptual timing deficits and behavioral measures of impulsiveness and inattention (Noreika et al., 2013). Conversely, musical training has been shown to have a profound influence on auditory-motor timing skills in children (Reifinger, 2006; Slater et al., 2013). In the present study, we asked whether playing a musical instrument can enhance the neural efficiency of auditory information encoding in the developing brain - as reflected by auditory-evoked response latencies, amplitudes, and measures of neural synchronization-and thereby counteract auditory deficits in $\mathrm{AD}(\mathrm{H}) \mathrm{D}$. We hypothesized that musically trained children might have larger Heschl's gyri (HGs) and faster auditory-evoked responses, which are advantageous for auditory, perceptual, and cognitive skills. Given the close interdependence between auditory and attentional functions, children with $\mathrm{AD}(\mathrm{H}) \mathrm{D}$ were expected to show the reversed pattern: reduced HG size and decreased neural efficiency. If temporal auditory encoding was affected, they might benefit from musical training.

\section{Materials and Methods}

Subjects and procedure. One hundred eleven children without developmental disorders (main group; mean \pm SD age at the outset of the study, 8.6 years \pm 9 months; sex, 54 males and 57 females) and 21 children with $\mathrm{AD}(\mathrm{H}) \mathrm{D}$ (mean $\pm \mathrm{SD}$ age, 8.9 years \pm 8 months; sex, 21 males) participated in the study (Table 1). All $\mathrm{AD}(\mathrm{H}) \mathrm{D}$ children had been diagnosed by a pediatrician or a child psychologist. The written diagnoses were based on the children's case histories (including typical behavioral patterns at home, in kindergarten, and at school) and direct behavioral observations in controlled playing and/or testing situations. Only children with a diagnosis according to the International Classification of Diseases, 10th Revision (ICD-10) classifications F98.8 (attention deficit disorder; ADD) or F90 (ADHD) were included. Children with known neurological problems or other developmental disorders, such as dyslexia or dyscalculia, were excluded from the study. To quantify and compare the strength of attention, hyperactivity, and impulsivity problems, the parents of all 132 participants were asked to fill out the German standardized questionnaire DCL-HKS (Diagnostic Checklist for Hyperkinetic Disorders; for parents), which is part of the DISYPS-KJ (Diagnostic System for Psychiatric Disorders in Children and Adolescents; Doepfner and Lehmkuhl, 2000) and conforms to the ICD-10 and Diagnostic and Statistical Manual of Mental Disorders, Fourth/Fifth Editions criteria. The DCL-HKS separately assesses the three dimensions "attentional problems," "hyperactivity," and "impulsivity" and combines them to evaluate overall severity of $\mathrm{AD}(\mathrm{H}) \mathrm{D}$, allowing a comparison with age-related norms. A percentile rank of 90 or higher is considered as an indication of $\mathrm{AD}(\mathrm{H}) \mathrm{D}$ (Doepfner and Lehmkuhl, 2000). In our study, $91 \%$ of children who were clinically diagnosed as $\mathrm{AD}(\mathrm{H}) \mathrm{D}$ were also identified as $\mathrm{AD}(\mathrm{H}) \mathrm{D}$ by $\mathrm{DCL}-\mathrm{HKS}$, but only $14 \%$ of the main group exceeded the age-related norm $\left(\chi^{2}=52.4\right.$, 
$\left.\mathrm{df}=1, p=5.4 \times 10^{-13}\right)$. Thus, there was a high level of agreement between DISYPS-based classifications and the pediatricians' diagnoses.

There were two measurement time points (MTP) at an interval of 13 months. At each MTP, there was a structural magnetic resonance imaging (MRI) and a functional magnetoencephalographic (MEG) session, as well as auditory and psychological tests to explore the elementary perceptual sensitivity (frequency discrimination), musical aptitude, and auditory-related cognitive functions (reading and writing skills). Although all $\mathrm{AD}(\mathrm{H}) \mathrm{D}$ children participated at both MTPs, five children in the main group were no longer available at MTP2. Moreover, for seven children [six of the main group and one of the $\mathrm{AD}(\mathrm{H}) \mathrm{D}$ group], the MRI or MEG data were not of sufficient quality for additional processing at either MTP1 or MTP2. These children were only included in crosssectional correlational analyses if the respective data were available; they were excluded from the longitudinal comparisons (Table 1).

Musical education and group assignment. $68 \%(n=76)$ of the main group and $43 \%(n=9)$ of the $\mathrm{AD}(\mathrm{H}) \mathrm{D}$ group received extracurricular music lessons but to a different extent. Approximately half of the children [main group, $n=54 ; \mathrm{AD}(\mathrm{H}) \mathrm{D}$ group, $n=7$ ] were participating in the German musical education program "JeKi" [Jedem Kind ein Instrument (An Instrument for Every Child); www.jedemkind.de/englisch/research. php]. The program was (and still is, as of 2014) running in the state (Bundesland) of Nordrhein-Westfalen and in the city of Hamburg. It aims to offer all primary school children the opportunity to learn an instrument of their own choice at school. Of the 71 children who did not participate in JeKi, 29 had had no instrumental lessons at all. The remaining 42 non-JeKi children were having regular extracurricular music lessons (Table 1).

A detailed questionnaire for parents was used to estimate the total amount of music practice during the entire life of each child, preceding each of two MTPs. A cumulative musical practice index, $I_{\mathrm{MP}}$, was calculated by combining parents' statements of the number of years of formal music education and the amount of time spent practicing where:

$$
I_{\mathrm{MP}}=\sum_{p} y_{p} h_{p}+\sum_{j} y_{j} h_{j}
$$

$y_{p}$ is the duration of private practice in years, $h_{p}$ is the frequency of private practice in hours per week, $y_{j}$ is the duration of JeKi practice in years, and $h_{j}$ is the frequency of JeKi practice in hours per week.

$I_{\mathrm{MP}}$ refers only to the time spent practicing at home; lessons are not included. If not stated otherwise, $I_{\mathrm{MP}}$ represents the summed private and JeKi-related practicing intensities. Duration and frequency of practice are equally weighted; this simplification appears to be justified because, to our knowledge, no study has explicitly compared the effectiveness of the two aspects. If a child played more than one instrument, the corresponding practicing times were added. Because only the practicing time at home is considered, $I_{\mathrm{MP}}$ may also be regarded as a measure of a child's motivation to invest time in musical activities, which may be interpreted as a sign of musicality. The validity of this assumption was confirmed by the close correlation between the $I_{\mathrm{MP}}$ and the score achieved at the musical aptitude test Intermediate Measures of Music Audiation (IMMA; Gordon, 1986), performed at MTP2 (main group, $r=0.62, p=1.1 \times$ $10^{-9}$; all children, $r=0.6, p=9.6 \times 10^{-11}$; Fig. $\left.1 C\right)$. Because many children were just at the outset of formal musical education at MTP1, it appeared to be more favorable to assign the participants to musical expertise groups according to the $I_{\mathrm{MP}}$ at MTP2, when interindividual differences were more pronounced. The distribution of $I_{\mathrm{MP}}$ was relatively broad and bimodal and exhibited a saddle point at 2.5 (Fig. 1A). The saddle point was used as a cutoff to separate the main group into low practicers (LPs; $I_{\mathrm{MP}} \leq 2.5 ; n=52$ ) and high practicers (HPs; $I_{\mathrm{MP}}>2.5$; $n=59$ ). The mean $I_{\mathrm{MP}}$ at MTP2 was 0.9 for LPs, 8.1 for HPs, and 1.4 for $\mathrm{AD}(\mathrm{H}) \mathrm{D}$ children (Fig. $1 B$ ). The JeKi participants had a mean $I_{\mathrm{MP}}$ of 3.5, approximately half of which was accounted for by the JeKi program (JeKi-related $\left.I_{\mathrm{MP}}, 1.6\right)$. HPs achieved substantially higher musicality scores at the IMMA test than LPs $\left(t_{(59.5)}=-7.2, p=8.8 \times 10^{-10}\right)$ and $\mathrm{AD}(\mathrm{H}) \mathrm{D}$ children $\left(t_{(23.3)}=-7, p=3.4 \times 10^{-7}\right)$. The latter two groups did not differ in this respect. There were no significant age differences between LPs, HPs, and $\mathrm{AD}(\mathrm{H}) \mathrm{D}$ children.

The children's socioeconomic background was determined by a comprehensive questionnaire for parents. A principal components analysis
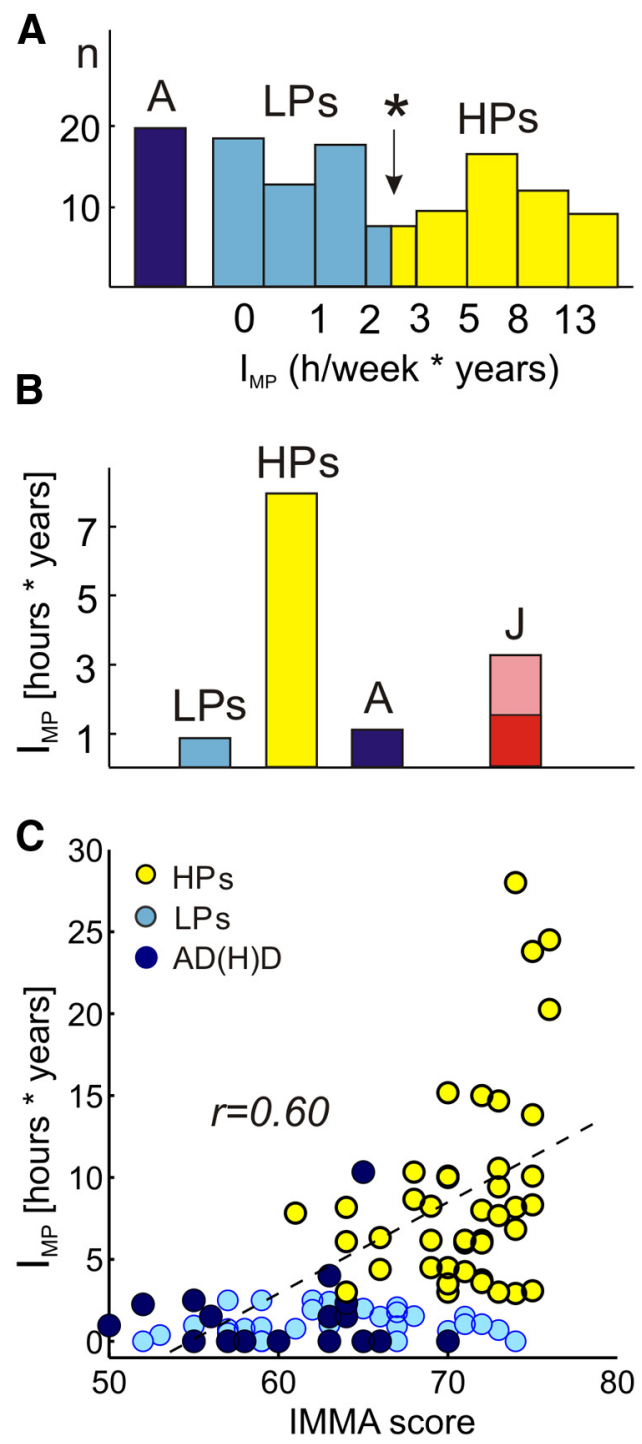

Figure 1. Intensity of musical activity. $\boldsymbol{A}$, Distribution of $I_{M P}$ for $A D(H) D$ children $(A)$ and for $\mathrm{LPs}$ and $\mathrm{HPs}$. The latter were defined by a cutoff value at the saddle point (asterisk at $I_{\mathrm{MP}}=2.5$ ). $\boldsymbol{B}$, Left, I IP group means (LP, HP, A); right, I IP of JeKi participants (J): on average, half of the practicing time was devoted to the JeKi program (dark red part) and the other half to extracurricular musical lessons (bright red part). C, Correlation of IMMA score and $I_{M P}$ at the second MTP.

revealed three relevant social dimensions: (1) education environment (including the mother's and father's highest professional degree and the number of books at home); (2) parental support (including the amount of parent-child communication, the frequency of common participation in cultural events, and the parents' personal interest in children's activities); and (3) resources and leisure activities (including courses in sports, arts, etc., and children's resources, such as their own room, personal computer, etc.). Parental income loaded as well on factors 1 and 3. The individual scores on each dimension were determined and compared across groups. $\mathrm{AD}(\mathrm{H}) \mathrm{D}$ children did not differ significantly in any dimension from LPs but achieved lower scores on factor 3 than HPs $\left(t_{(78)}=-3.0, p=0.003\right)$. Moreover, LPs were characterized by slightly lower scores on factors $1\left(t_{(83.7)}=-2.6, p=0.011\right)$ and $3\left(t_{(95.7)}=-2.6\right.$, $p=0.012)$ than HPs.

LPs had significantly higher DCL-HKS scores in the DISYPS than HPs (Mann-Whitney $U$ test, $U=1034, z=2.7, p=0.006$ ). This suggests that musical expertise is associated with favorable attentional skills and a lower risk for $\mathrm{AD}(\mathrm{H}) \mathrm{D}$.

Morphometry. AC anatomy was investigated by structural MRI. The individual surface of $\mathrm{AC}$ was $3 \mathrm{D}$ reconstructed from the MRI slices, 


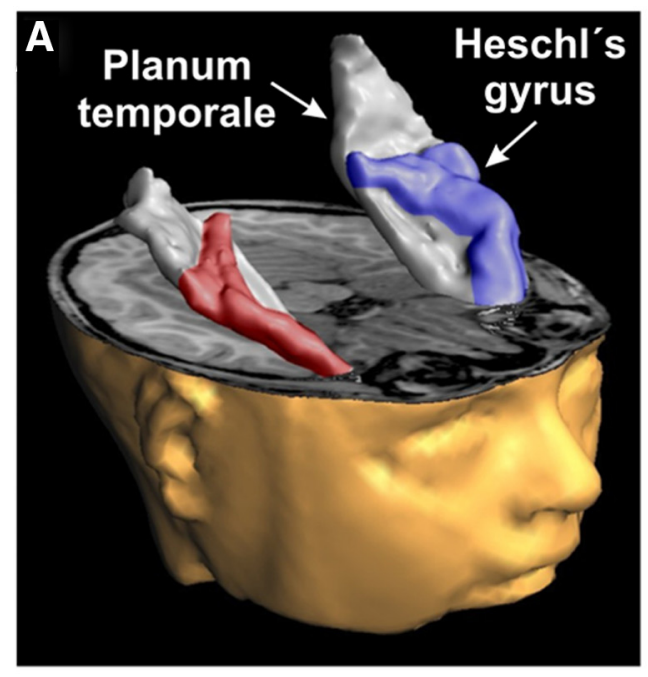

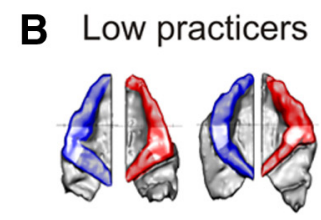
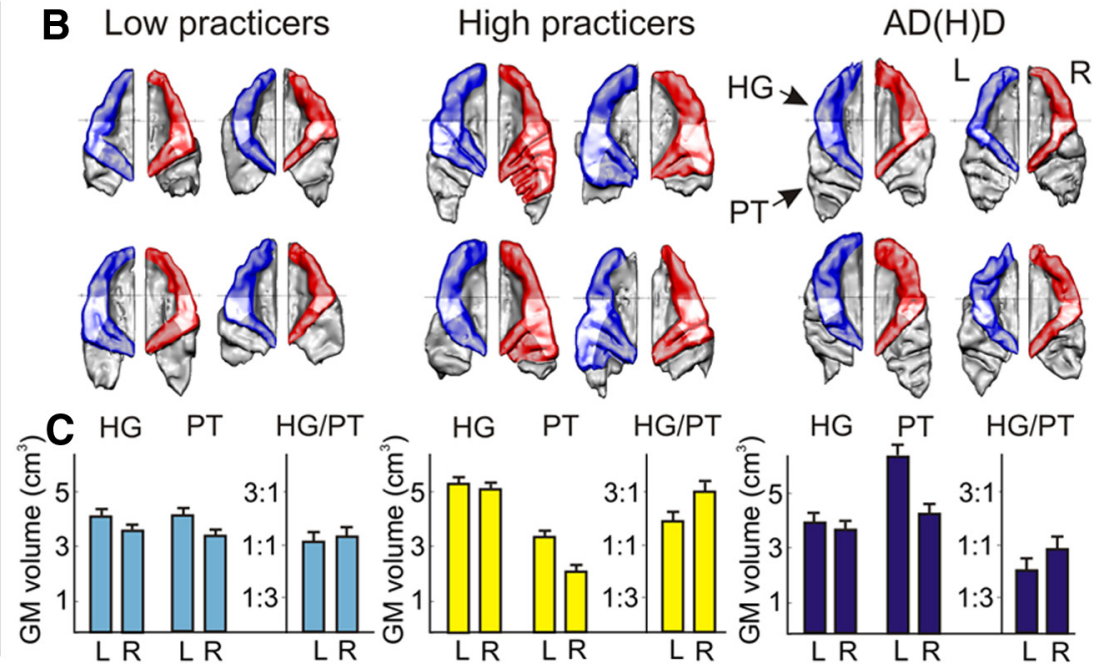

Figure 2. Individual morphology and relative gray matter volume of HG and PT. A, 3D reconstruction of an individual AC. HGs and its duplications are colored in blue (left hemisphere) and red (right hemisphere). $\boldsymbol{B}$, A top view of 12 exemplary individual ACs reveals the characteristic large variability in size, gyrification, and hemispheric asymmetry of HG and PT. $\boldsymbol{C}$, Bar graphs showing the gray matter (GM) volumes of HG, PT, and HG/PT ratio in both hemispheres for the three groups. L, Left; R, right.

uncovering the complex shape of the HG, including primary auditory areas and the posteriorly located planum temporale (PT; Fig. $2 A$ ). In the literature, HG boundaries are defined in two different ways: (1) the region of primary AC within the HG; and (2) the complete HG, including HG duplications. Traditionally, the primary AC has been localized on the first transverse HG convolution (Steinmetz et al., 1989; Rademacher et al., 1993; Penhune et al., 1996, 2003). However, some cytoarchitectonic and functional imaging studies have shown that the primary AC is not necessarily confined to the first anterior HG but may partially occupy HG duplications (Rademacher et al., 2001; Da Costa et al., 2013; Herdener et al., 2013). HG morphology varies considerably across individuals. It ranges from a simple single gyrus to a variety of duplicated or even triplicated gyri, including either partial duplications (lateral, common stem, or medial) and/or complete posterior duplications (Schneider et al., 2005, 2009; Wengenroth et al., 2010, 2014; Marie et al., 2013). Recent fMRI studies have provided evidence for an anatomical-functional relationship, such that the activation of HG and its duplications follows the different morphological variants (Warrier et al., 2009; Da Costa et al., 2013; Wengenroth et al., 2014). The first complete Heschl's sulcus has been considered as the posterior border of HG (Leonard et al., 1998; Schneider et al., 2005) that separates the functional-anatomical entity of HG, including both primary core and secondary belt areas, from PT and furthermore divides AC into two parts: (1) an anterior auditory stream, including HG and anterior superior temporal gyrus (aSTG); and (2) a posterior stream, including PT. The $y=0$ line was defined in all cases as an anterior borderline that separates HG from aSTG.

The $3 \mathrm{D}$ gray matter surface reconstructions of $\mathrm{AC}$ were calculated from T1-weighted structural MRI data (TrioTim, 3 Tesla; Siemens) after segmentation by using Brain Voyager software (Brain Innovation). All brain images were corrected for inhomogeneity and rotated in the direction of the anteroposterior commissural line but were not normalized to account for potential age-related changes between the two MTPs in the follow-up design. However, no such changes were observed for any of the tested groups. Using standard definitions of anatomical AC landmarks, the sagittal MRI slices of the individual ACs were segmented along the Sylvian fissure to obtain PT and HG (Schneider et al., 2005, 2009). The inclusion range of image gray values was calculated in a box around left and right AC. For gray matter surface reconstruction and morphometry, the "gray value inclusion range" was defined individually from the intensity histogram for each left and right AC by identifying the following: (1) the third-amplitude side lobe of the gray matter peak distribution toward CSF; (2) the saddle point between the gray and white matter peak. All gray value voxels inside this inclusion range were marked and used for 3D reconstruction and morphometry. The non-automated parts of this structural analysis, in particular the identification of landmarks from the individual 3D surface reconstructions of $\mathrm{AC}$, were obtained by observers who were blind to subject, group, and hemisphere.

Magnetoencephalography. The function of AC was investigated by MEG recordings in response to acoustic stimuli. Using a Neuromag-122 whole-head MEG system, auditory-evoked fields were recorded in response to seven different sampled instrumental sounds (trumpet, flute, bass clarinet, piano, guitar, timpani, and plucked violin) and four synthetically generated harmonic complex sounds with a duration of $500 \mathrm{~ms}$ and a stimulus onset asynchrony randomized between 700 and $1000 \mathrm{~ms}$. Each of the 11 stimuli was presented 100 times in pseudorandomized order. The children were instructed to listen to the sounds passively. They watched a silent video to keep them quiet and to reduce the probability of artifacts. This strategy was particularly important (and successful) for children with $\mathrm{AD}(\mathrm{H}) \mathrm{D}$. The 100 repetitions of each stimulus increased the signal-to-noise ratio to enable robust source modeling as a basis for the additional analysis of the time course, latencies, and amplitudes of the auditory-evoked fields. The procedure had been tested and optimized in pilot studies before the study. The duration of the measurement session was $\sim 15 \mathrm{~min}$. Cortical responses were averaged using the BESA program (BESA GmbH, Graefelfing, Germany) and collapsed into an individual grand average for source analysis (1100 averages). After artifact rejection $(\sim 10 \%)$, the total amount of averaged epochs was reduced to $\sim 1000$ trials. The source activity of the primary evoked response (P1) was separated from the later secondary negative $\mathrm{N} 1$ response complex, peaking at 200-270 ms after stimulus onset in our tested children, by spatiotemporal source modeling, using one equivalent dipole in each hemisphere. Signal strength was calculated relative to a $100 \mathrm{~ms}$ prestimulus baseline. For P1, the fitting intervals were individually adjusted according to the time interval around the respective peak, as defined by its half-side lobes (the time points at which the amplitude of the peak is halved). The P1 fitting results of our model were robust in all cases. Because the subsequent N1 response is still weak in primary school children (Ponton et al., 2002), it could not be observed in all subjects. Furthermore, at that age, the N1 peak latency is usually delayed $(\sim 200-$ $270 \mathrm{~ms})$ compared with adults $(\sim 100 \mathrm{~ms}$; Fig. $3 B)$. Therefore, in later analyses, we only included the more robust $\mathrm{P} 1$ amplitudes and latencies and the absolute peak latency difference $\left(\mathrm{P} 1_{\text {right }- \text { left }}\right)$, an indicator of the functional synchronization between right and left AC.

Auditory tests. For psychoacoustic testing, the "Dinosaur" threshold estimation program (Sutcliffe and Bishop, 2005; modified version: Huss et al., 2011) was used. In a two-alternative forced-choice paradigm, two pure tones were presented at an intensity of $65 \mathrm{~dB}$ SPL, each with durations of $200 \mathrm{~ms}$ and separated by an interstimulus interval of $500 \mathrm{~ms}$. One 
Low practicers

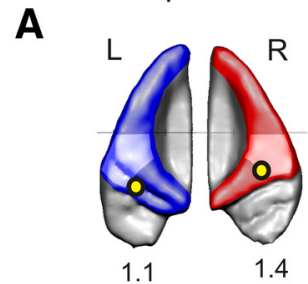

High practicers

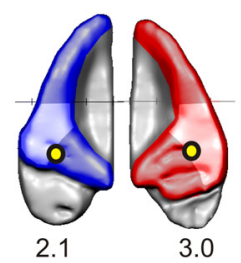

$A D(H) D$

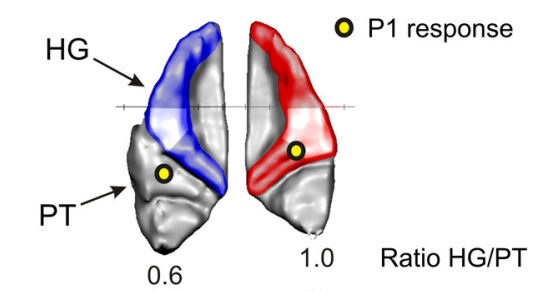

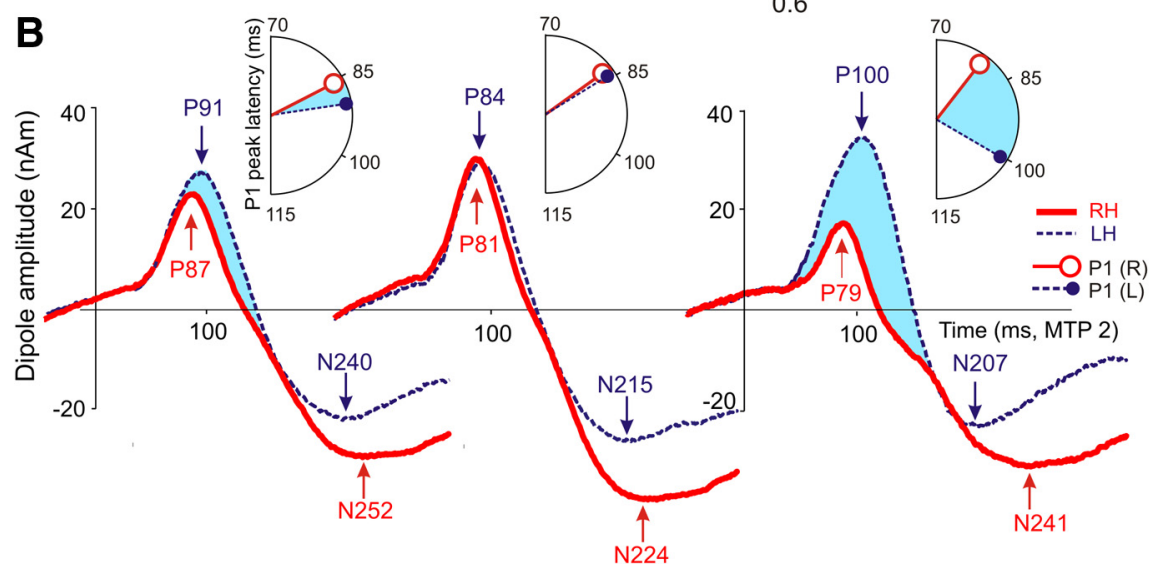

Figure 3. Localization, time course, and bilateral asynchrony of auditory-evoked P1 source activity in response to the sounds of various musical instruments and artificial tones. $A$, The primary P1 responses (yellow circles) are projected onto the group-averaged surface meshes; $P 1$ sources localized robustly on $H G$, except for $A D(H) D$ children in the left hemisphere. Mean gray matter ratios HG/PT are indicated by numbers. L, Left; $R$, right. $\boldsymbol{B}$, Time courses of the averaged source waveforms for the right (red curve; RH) and left (blue curve; LH) hemisphere. Indicated P1 and N1 latencies refer to peak level. Mean latency differences between the two hemispheres are displayed in a clockwise manner. HPs demonstrate a remarkable left-right synchronization of the primary P1. Conversely, LPs show a slight bilateral P1 asynchrony; for AD(H)D children, the asynchrony is more pronounced (blue shaded area).

of the tones was a fixed standard with a frequency of $500 \mathrm{~Hz}$, and the other tone had variable frequency. The maximum pitch difference between the stimuli was two semitones. Children were introduced to two cartoon birds. They were told that each bird would make a sound and the child had to decide which bird's sound was higher. Feedback was given online throughout the course of the experiment. A staircase procedure was used to adapt stimulus difficulty to the participant's previous answer. Therefore, the number of trials completed by individual participants varied slightly (maximum number of trials, 40 ). The threshold score (just noticeable frequency difference) was based on the point of $75 \%$ correct responses for the last four reversals.

At MTP2, the musical aptitude test IMMA by Gordon (1986) was also presented. The test measures the ability to internalize musical structures and to detect tonal or rhythmic modifications in sequentially presented patterns. The children listened to 40 pairs of tone sequences and 40 pairs of rhythms and made a same/different judgment by circling a pair of same or different faces on the answer sheet. The subtest scores were combined to generate a composite music aptitude score with a maximum of 80 correct answers. Because of the high correlation between the tonal and rhythm subtest $\left(r=0.81, p=13.5 \times 10^{-21}\right)$, the individual composite scores were used for additional data analysis.

Cognitive tests. At MTP1, the children's nonverbal IQ was tested with the Culture Fair Intelligence Test (CFT1) of Cattell et al. (1997). The CFT1 consists of five subtests (substitutions, mazes, classifications, similarities, and matrices) and assesses the children's general fluid intelligence. At MTP2, i.e., 13 months later, the revised version of the CFT20 (CFT20-R; Weiß, 2008) for slightly older children was used. The CFT20-R comprises the four subtests substitutions, classifications, matrices, and reasoning.

Reading and spelling skills were determined at both MTPs. Reading fluency was determined by the German speed test Salzburger Lesescreening (SLS 1-4; Mayringer and Wimmer, 2003). The test contains 70 statements (e.g., "Bananas are blue"). The children had 3 min to successively

read as many statements as possible and to decide whether they were true or false. A reading quotient was determined, referring to the age norms and scaled like the IQ (mean $\pm \mathrm{SD}$, $100 \pm 15)$.

Spelling skills were assessed by the German test Hamburger Schreibprobe (HSP 1-9; May, 2002). Words and sentences were dictated by the experimenter. The children's task was to write them next to the corresponding pictures. The test took $\sim 20 \mathrm{~min}$. The HSP provided measures for the following: (1) three spelling strategies (alphabetic: phonological correctness; orthographic: consideration of learned rules; morphematic: correct usage of smallest grammatical units in language, such as word roots, affixes, etc.); and (2) the number of correctly spelled difficult word spots ("grapheme hits"). $T$ values were determined to compare performance with age-related norms.

All experimental procedures were approved by the relevant local research ethics committee.

Statistical analyses. For the correlational analyses between structural, functional, and behavioral measures, we used Pearson's coefficients if, according to the Kolmogorov-Smirnov test, both tested variables were normally distributed. Otherwise, the nonparametric Spearman's $\rho$ was used. Because the interindividual variability in musical expertise increased with age, correlations at MTP2 are more informative with regard to potential musical training effects. Hence, if not stated otherwise, indicated correlations refer to MTP2.

When testing for effects related to reading and literacy, only the main group (LPs and HPs) was considered to avoid biasing by the fact that most $\mathrm{AD}(\mathrm{H}) \mathrm{D}$ children showed slight impairments in these domains and did not play a musical instrument.

For the analysis of potential differences in gray matter volumes and their changes over time, a four-way repeated-measures ANOVA was calculated for the independent variables group [HPs, LPs, AD(H)D], hemisphere (right, left), AC region (HG, PT), and MTP $(1,2)$. Neurofunctional MEG effects were separately analyzed in three-way ANOVAs (group, hemisphere, MTP) for the dependent variables P1 latency and P1 amplitude. Moreover, a two-way ANOVA (group, MTP) was performed for the dependent variable bilateral P1 asynchrony (|right-left|), which indicates the extent of interhemispheric latency differences. To provide a common overview of group differences and developmental changes seen in the MRI (Table 2) and MEG parameters (Table 3), additional ANOVAs were calculated separately for each hemisphere and cortical region (MRI only). The considered dependent variables were gray matter volume, gray matter ratio (HG/PT), P1 amplitude, P1 latency, bilateral $\mathrm{P} 1$ asynchrony, and P1 latency reduction (MTP2 - MTP1). In case of a significant main effect group and homogeneous error variances (as indicated by Levene's test), post hoc comparisons between LPs, HPs, and $\mathrm{AD}(\mathrm{H}) \mathrm{D}$ children were performed with Scheffé's test (including a Bonferroni's correction for multiple comparisons). Otherwise, Tamhane's test was used. In case of significant interactions, the mean values of interest were compared with the Tukey's HSD test.

Two discriminant analyses were then performed to investigate how well different neural parameters segregate (1) LPs versus HPs and (2) the main versus $\mathrm{AD}(\mathrm{H}) \mathrm{D}$ group. The predictor variables were $\mathrm{HG}$ volume right, HG volume left, PT volume right, PT volume left, and bilateral P1 asynchrony. In addition, a linear multiple regression model was calculated (see Results).

All statistical analyses were performed with the software package IBM SPSS Statistics version 21.0.0.0. 
Table 2. ANOVA results for the MRI-based morphology of AC

\begin{tabular}{|c|c|c|c|c|c|c|c|c|}
\hline & MTP & $\begin{array}{l}\operatorname{LPs}(n=50 ; \\
29 \text { males, } \\
21 \text { females) }\end{array}$ & $\begin{array}{l}\operatorname{HPs}(n=52 ; \\
20 \text { males, } \\
32 \text { females) }\end{array}$ & $\begin{array}{l}\text { AD }(H) D \\
(n=21 ; \\
\text { all males) }\end{array}$ & $\begin{array}{l}\text { Significance } \\
\text { of MTP }\end{array}$ & Significance of group & Post hoc comparisons for group & $\begin{array}{l}\text { Significance of group } \\
\text { for boys only }\end{array}$ \\
\hline \multirow[t]{2}{*}{ HG (R) volume $\left(\mathrm{mm}^{3}\right)$} & 1 & $3685 \pm 156$ & $5173 \pm 153$ & $727 \pm 241$ & \multirow[t]{2}{*}{ n.s. } & \multirow{2}{*}{$\begin{array}{l}F_{(2,120)}=28.2 ; \\
p=8.9 \times 10^{-11} \\
\text { partial } \eta^{2}=0.32\end{array}$} & \multirow{2}{*}{$\begin{array}{l}\text { LP versus } H P, p=1.3 \times 10^{-9} ; \\
\quad \text { P versus } A D(H) D, \text { n.s.; } \\
\quad H P \text { versus } A D(H) D, p=4.8 \times 10^{-6}\end{array}$} & \multirow{2}{*}{$\begin{array}{l}F_{(2,67)}=11.3 ; \\
\quad p=6.1 \times 10^{-5} \\
\quad \text { partial } \eta^{2}=0.25\end{array}$} \\
\hline & 2 & $3692 \pm 152$ & $5188 \pm 149$ & $3726 \pm 234$ & & & & \\
\hline \multirow[t]{2}{*}{ HG (L) volume $\left(\mathrm{mm}^{3}\right)$} & 1 & $4193 \pm 190$ & $5377 \pm 186$ & $3998 \pm 293$ & \multirow[t]{2}{*}{ n.s. } & \multirow{2}{*}{$\begin{array}{l}F_{(2,120)}=13.5 ; \\
\quad p=5 \times 10^{-6} \\
\quad \text { partial } \eta^{2}=0.18\end{array}$} & \multirow{2}{*}{$\begin{array}{l}\text { LP versus } H P, p=1.2 \times 10^{-4} ; \\
\quad \operatorname{PP} \text { versus } A D(H) D, \text { n.s.; } \\
\quad H P \text { versus } A D(H) D, p=5.3 \times 10^{-5}\end{array}$} & \multirow{2}{*}{$\begin{array}{l}F_{(2,67)}=9.2 ; \\
\quad p=2.9 \times 10^{-4} ; \\
\text { partial } \eta^{2}=0.22\end{array}$} \\
\hline & 2 & $4193 \pm 193$ & $5409 \pm 190$ & $3937 \pm 298$ & & & & \\
\hline \multirow[t]{2}{*}{ PT (R) volume $\left(\mathrm{mm}^{3}\right)$} & 1 & $3453 \pm 181$ & $2203 \pm 177$ & $4359 \pm 279$ & \multirow[t]{2}{*}{ n.s. } & $F_{(2,120)}=27.3$ & \multirow{2}{*}{$\begin{array}{l}\text { LP versus } H P, p=4 \times 10^{-6} \\
\quad \operatorname{LP} \text { versus } A D(H) D, p=0.026 ; \\
\quad H P \text { versus } A D(H) D, p=3.5 \times 10^{-9}\end{array}$} & \multirow{2}{*}{$\begin{array}{l}F_{(2,67)}=8.8 \\
\quad p=4.1 \times 10^{-4} \\
\text { partial } \eta^{2}=0.21\end{array}$} \\
\hline & 2 & $3488 \pm 171$ & $2163 \pm 168$ & $4344 \pm 265$ & & $\begin{array}{l}p=2 \times 10^{-10} \\
\text { partial } \eta^{2}=0.31\end{array}$ & & \\
\hline \multirow[t]{2}{*}{ PT (L) volume $\left(\mathrm{mm}^{3}\right)$} & 1 & $4188 \pm 221$ & $3475 \pm 216$ & $6304 \pm 341$ & \multirow[t]{2}{*}{ n.s. } & $F_{(2,120)}=27.5$ & \multirow{2}{*}{$\begin{array}{l}\text { LP versus HP, n.S.; } \\
\quad L P \text { versus } A D(H) D, p=1.5 \times 10^{-6} ; \\
\quad H P \text { versus } A D(H) D, p=1.6 \times 10^{-10}\end{array}$} & \multirow{2}{*}{$\begin{array}{l}F_{(2,67)}=10.5 \\
\quad p=1 \times 10^{-4} \\
\quad \text { partial } \eta^{2}=0.24\end{array}$} \\
\hline & 2 & $4207 \pm 213$ & $3429 \pm 209$ & $6445 \pm 398$ & & $\begin{array}{l}p=2 \times 10^{-10} \\
\text { partial } \eta^{2}=0.31\end{array}$ & & \\
\hline \multirow[t]{2}{*}{ HG/PT (R) } & 1 & $1.40 \pm 0.18$ & $3.00 \pm 1.18$ & $0.98 \pm 0.28$ & \multirow[t]{2}{*}{ n.s. } & $F_{(2,120)}=30$ & \multirow{2}{*}{$\begin{array}{l}\text { LP versus } H P, p=7.6 \times 10^{-8} ; \\
\quad L P \text { versus } A D(H) D, \text { n.s.; } \\
\quad H P \text { versus } A D(H) D, p=5.3 \times 10^{-11}\end{array}$} & \multirow{2}{*}{$\begin{array}{l}F_{(2,67)}=14.6 \\
\quad p=5.5 \times 10^{-6} \\
\quad \text { partial } \eta^{2}=0.3\end{array}$} \\
\hline & 2 & $1.37 \pm 0.18$ & $3.00 \pm 1.18$ & $0.96 \pm 0.28$ & & $\begin{array}{l}p=2.8 \times 10^{-11} \\
\text { partial } \eta^{2}=0.33\end{array}$ & & \\
\hline \multirow[t]{2}{*}{ HG/PT (L) } & 1 & $1.15 \pm 0.15$ & $2.05 \pm 0.15$ & $0.68 \pm 0.23$ & \multirow[t]{2}{*}{ n.s. } & $F_{(2,120)}=16.9 ;$ & \multirow{2}{*}{$\begin{array}{l}\text { LP versus } H P, p=3.3 \times 10^{-4} \\
\quad L P \text { versus } A D(H) D, p=2.4 \times 10^{-5} \\
\quad H P \text { versus } A D(H) D, p=2.4 \times 10^{-5}\end{array}$} & \multirow{2}{*}{$\begin{array}{l}F_{(2,67)}=7.5 \\
\quad p=0.001 \\
\quad \text { partial } \eta^{2}=0.1\end{array}$} \\
\hline & 2 & $1.13 \pm 0.15$ & $2.05 \pm 0.15$ & $0.62 \pm 0.23$ & & $\begin{array}{l}p=3.3 \times 10^{-7} \\
\text { partial } \eta^{2}=0.22\end{array}$ & & \\
\hline
\end{tabular}

ANOVA group comparisons for MRI-based gray matter volumes of HG, PT, and HG/PT ratio in the right ( $\mathrm{R}$ ) and left (L) hemisphere for both MTPs. Morphometric values: mean \pm SEM (cubic millimeters). To test whether the unequal gender distributions in the three groups [all $\mathrm{AD}(\mathrm{H}) \mathrm{D}$ children were male] may be responsible for some of the observed effects, the right column shows the corresponding results for boys only.

Table 3. ANOVA results for the MEG-based auditory-evoked $P 1$ response

\begin{tabular}{|c|c|c|c|c|c|c|c|c|}
\hline & MTP & $\begin{array}{l}\text { LPs ( } n=49 ; \\
29 \text { males, } \\
20 \text { females) }\end{array}$ & $\begin{array}{l}\operatorname{HPs}(n=53 ; \\
22 \text { males, } \\
31 \text { females) }\end{array}$ & $\begin{array}{l}\mathrm{AD}(\mathrm{H}) \mathrm{D} \\
(n=20 ; \\
\text { all males) }\end{array}$ & $\begin{array}{l}\text { Significance } \\
\text { of MTP }\end{array}$ & Significance of group & Post hoc comparisons of group & $\begin{array}{l}\text { Significance of group } \\
\text { for boys only }\end{array}$ \\
\hline P1 (R) amplitude (nAm) & 1 & $24.4 \pm 1.5$ & $34.6 \pm 1.4$ & $19 \pm 2.3$ & n.s. & $\begin{array}{l}F_{(2,119)}=28.6 \\
\quad p=7.3 \times 10^{-11} \\
\text { partial } \eta^{2}=0.32\end{array}$ & $\begin{array}{l}\text { LP versus } H P, p=0.0003 ; \\
\quad L P \text { versus } A D(H) D \text {, n.s.; } \\
\quad H P \text { versus } A D(H) D, p=7.8 \times 10^{-6}\end{array}$ & $\begin{array}{l}F_{(2,119)}=17.1 \\
\quad p=9.8 \times 10^{-7} \\
\quad \text { partial } \eta^{2}=0.33\end{array}$ \\
\hline \multirow[t]{2}{*}{ P1 (L) amplitude (nAm) } & 1 & $25.6 \pm 1.4$ & $36.9 \pm 1.3$ & $19.4 \pm 2.2$ & \multirow[t]{2}{*}{ n.s. } & \multirow{2}{*}{$\begin{array}{l}F_{(2,119)}=3.6 ; \\
\quad p=0.032 ; \\
\quad \text { partial } \eta^{2}=0.06\end{array}$} & \multirow{2}{*}{ 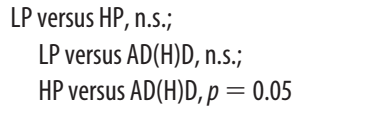 } & \multirow[t]{2}{*}{ n.s. } \\
\hline & 2 & $32.6 \pm 1.6$ & $36.8 \pm 1.6$ & $28.6 \pm 2.5$ & & & & \\
\hline P1 (R) latency (ms) & 2 & $87 \pm 1$ & $81 \pm 1$ & $79 \pm 2$ & $\begin{array}{l}F_{(1,119)}=126.2 ; \\
\quad p=2.1 \times 10^{-20} \\
\quad \text { partial } \eta^{2}=0.52\end{array}$ & $\begin{array}{l}F_{(2,119)}=4.6 ; \\
\quad p=0.012 ; \\
\quad \text { partial } \eta^{2}=0.07\end{array}$ & $\begin{array}{l}\text { LP versus HP, n.s.; } \\
\text { LP versus } A D(H) D, p=0.016 ; \\
\text { HP versus } A D(H) D \text {, n.s. }\end{array}$ & $\begin{array}{l}F_{(2,119)}=4.1 \\
\quad p=0.02 ; \\
\quad \text { partial } \eta^{2}=0.11\end{array}$ \\
\hline \multirow[t]{2}{*}{ P1 (L) latency (ms) } & 1 & $96 \pm 2$ & $92 \pm 2$ & $103 \pm 3$ & \multirow{2}{*}{$\begin{array}{l}F_{(1,119)}=81.2 \\
\quad p=1 \times 10^{-13} \\
\quad \text { partial } \eta^{2}=0.41\end{array}$} & \multirow{2}{*}{$\begin{array}{l}F_{(2,119)}=10.2 ; \\
\quad p=8 \times 10^{-5} ; \\
\quad \text { partial } \eta^{2}=0.15\end{array}$} & \multirow{2}{*}{$\begin{array}{l}\text { LP versus } H P, p=0.04 \\
\quad L P \text { versus } A D(H) D, p=0.05 \\
\quad H P \text { versus } A D(H) D, p=1.3 \times 10^{-4}\end{array}$} & \multirow{2}{*}{$\begin{array}{l}F_{(2,119)}=5.7 \\
\quad p=0.005 \\
\quad \text { partial } \eta^{2}=0.14\end{array}$} \\
\hline & 2 & $91 \pm 2$ & $84 \pm 2$ & $100 \pm 3$ & & & & \\
\hline \multirow{2}{*}{$\begin{array}{l}\text { Bilateral P1 asynchrony } \\
\qquad|\mathrm{R}-\mathrm{L}| \text { (ms) }\end{array}$} & 1 & $7.4 \pm 0.9$ & $4.4 \pm 0.9$ & $22.9 \pm 1.4$ & \multirow[t]{2}{*}{ n.s. } & $F_{(2,119)}=61.5$ & $L P$ versus $H P, p=0.016$ & \multirow{2}{*}{$\begin{array}{l}F_{(2,119)}=31.7 \\
\quad p=1.9 \times 10^{-10} ; \\
\quad \text { partial } \eta^{2}=0.48\end{array}$} \\
\hline & 2 & $6.9 \pm 1.0$ & $3.9 \pm 1.0$ & $22.2 \pm 1.6$ & & $\begin{array}{l}p=4.6 \times 10^{-19} \\
\text { partial } \eta^{2}=0.51\end{array}$ & $\begin{array}{l}L P \text { versus } A D(H) D, p=8.4 \times 10^{-6} \\
H P \text { versus } A D(H) D, p=6.4 \times 10^{-7}\end{array}$ & \\
\hline
\end{tabular}

ANOVA group comparisons for MEG-based auditory-evoked P1. Right (R) and left (L) hemispheric amplitudes, latencies, and bilateral asynchronies at both MTPs and P1 latency reduction over time. P1 amplitude (nanoamperemeter; $n$ Am) and latency (ms): Peak value and time point of the primary response arising from $\mathrm{HG}$; Bilateral P1 asynchrony: $\mathrm{P} 1$ latency difference $|\mathrm{R}-\mathrm{L}|$; mean $\pm \mathrm{SEM}$. To test whether the unequal gender distributions in the three groups [all AD(H)D children were male] may be responsible for some of the observed effects, the right column shows the corresponding results for boys only.

\section{Results}

\section{Neuroanatomical correlates of auditory ability and dysfunction}

There was substantial inter-individual variability in the size of HG and PT and the number of HG duplications in both hemispheres (Fig. 2B). As evident from Table 2 and the bar graphs in Figure 2C, HPs had larger HGs $\left(5287 \mathrm{~mm}^{2}\right)$ than LPs $\left(3941 \mathrm{~mm}^{2}\right)$ and $\mathrm{AD}(\mathrm{H}) \mathrm{D}$ children $\left(3847 \mathrm{~mm}^{2}\right)$. The effect was observed for both hemispheres but was more pronounced on the right side. Conversely, PTs were considerably larger in $\mathrm{AD}(\mathrm{H}) \mathrm{D}$ children $\left(5363 \mathrm{~mm}^{2}\right)$ than in LPs $\left(3834 \mathrm{~mm}^{2}\right)$ and HPs $\left(2817 \mathrm{~mm}^{2}\right)$. As shown in Table 2, the PT enlargement in $\mathrm{AD}(\mathrm{H}) \mathrm{D}$ children was significant for both hemispheres, albeit more pronounced on the left side. Hence, there was a clear volumetric predominance of HG over PT in HPs, with a mean HG/PT ratio that was approximately twice that of musically inexperienced children (2.5 in HPs vs 1.2 in LPs; Fig. 3A, Table 2). Conversely, $\mathrm{AD}(\mathrm{H}) \mathrm{D}$ children showed a low HG/PT ratio, especially on the left side (mean, 0.6). Figure $4 F$ shows that the left $\mathrm{HG} / \mathrm{PT}$ ratio was negatively correlated with the DISYPS-based DCL-HKS index of AD(H)D symptom strength $\left(r=-0.44, p=3.2 \times 10^{-7}\right)$. The HG/PT ratio of the right hemisphere was strongly correlated with $I_{\mathrm{MP}}$ 

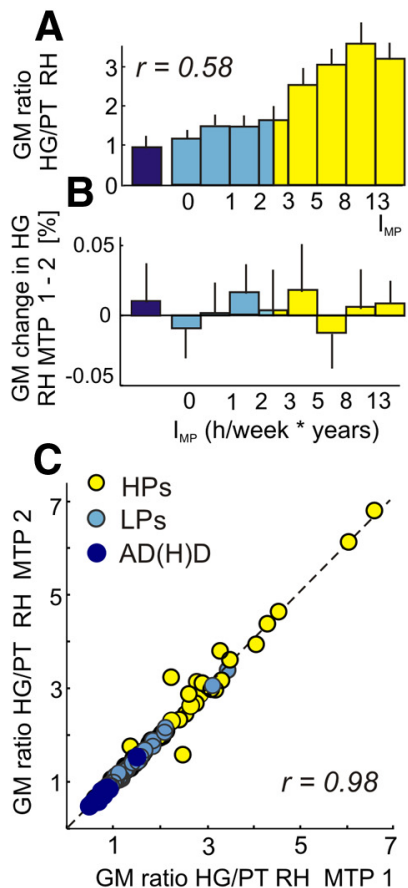

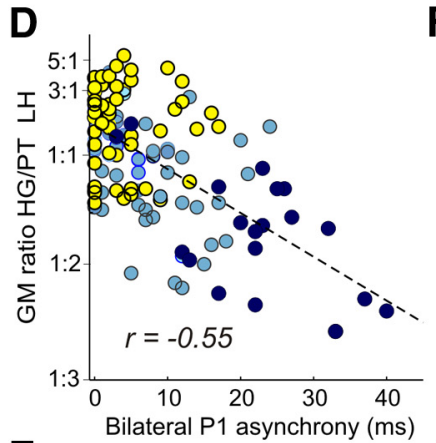

E

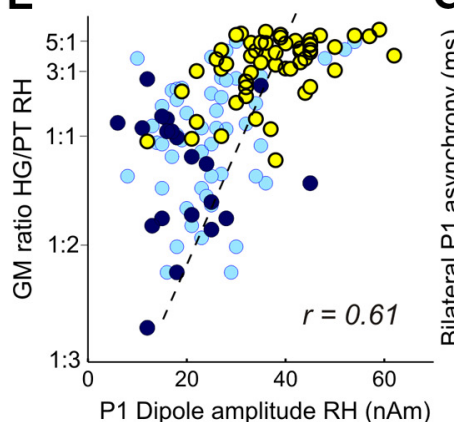

$\mathbf{F}$
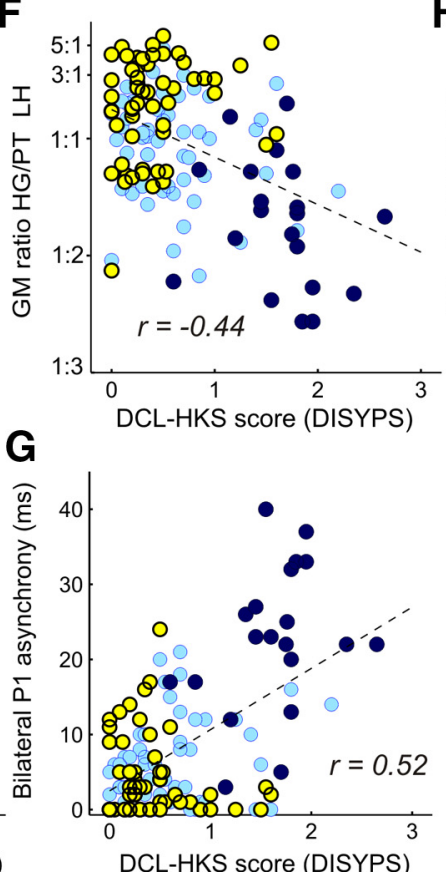

H
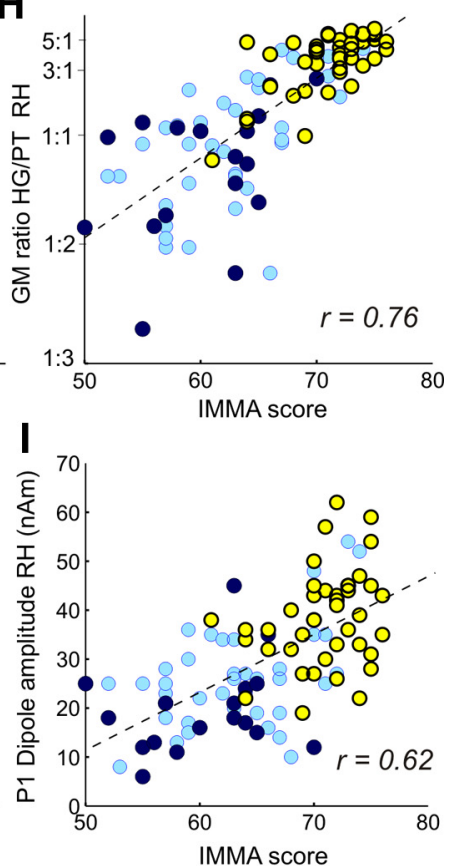

Figure 4. Anatomical and functional markers of musicality and $A D(H) D$. $A$, Correlation of right hemispheric gray matter (GM) ratio of HG/PT and musical practicing index. $\boldsymbol{B}$, Percentage of GM changes in HG between the first and second MRI MTP as a function of musical practice. C, Correlation between the HG/PT ratios at both MTPs. D, Correlation of functional and anatomical asymmetries. The P1 synchrony between the right and left hemisphere increases significantly with the GM ratio HG/PT, indicating that the strong asynchrony observed in $A D(H) D$ children is related to a relative dominance of the PT. E, Correlation between P1 dipole amplitude and HG/PT ratio in the right hemisphere. F-I, Correlations of AD(H)D symptom strength (DCL-HKS score in DISYPS) and IMMA score with structural and functional parameters, respectively. Because of the slightly skewed distribution of "GM ratio HG/PT LH," this variable was inversely transformed (1/value) for the correlational analysis in $\boldsymbol{D}$ and $\boldsymbol{F}$. LH, Left hemisphere; RH, right hemisphere.

(main group only, $r=0.58, p=3 \times 10^{-12}$; all children, Fig. $4 A$ ) and the musicality score achieved at the IMMA (main group only, $r=0.69, p=1.1 \times 10^{-13}$; all children, Fig. $\left.4 H\right)$. The correlations with $I_{\mathrm{MP}}$ were already evident at the first MTP when musical experience was still low in most subjects $(r=0.57, p=3 \times$ $\left.10^{-12}\right)$. Even for the JeKi participants, the time invested in practicing the JeKi instrument at home was related to right HG volumes $[r=0.28, p=0.048 ; \mathrm{AD}(\mathrm{H}) \mathrm{D}$ children excluded].

There was an interaction of region $\times$ hemisphere $\left(F_{(1,120)}=\right.$ $19.28 ; p=2.5 \times 10^{-5}$; partial $\left.\eta^{2}=0.14\right)$ : PTs were larger on the left $\left(4675 \mathrm{~mm}^{2}\right)$ than on the right side $\left(3335 \mathrm{~mm}^{2} ; p \leq 0.01\right)$. For $\mathrm{HG}$, this asymmetry was smaller and not significant. Correspondingly, the HG/PT ratio was higher for the right than for the left hemisphere $\left(F_{(1,120)}=0.0001\right.$; partial $\left.\eta^{2}=0.12\right)$.

We also compared the gray matter volume of right $\mathrm{HG}$ at MTP1 with the time that was subsequently invested into instrumental practice ( $I_{\mathrm{MP}}$ between the two MTPs). The extent of musical practice before the study $\left(I_{\mathrm{MP}}\right.$ at MTP1) was partialled out to control for differences in early musical training. Nevertheless, there was a robust correlation between right $\mathrm{HG}$ gray matter volume and the musical practicing behavior from MTP1 to MTP2 $\left(r=0.45, p=3 \times 10^{-6}\right)$. This precludes the possibility that the observed relation between neuroanatomy and the actual practicing intensity was mediated by earlier training influences.

To estimate the relative importance of musical training versus musical aptitude for the right HG/PT ratio, a linear multiple regression model with $I_{\mathrm{MP}}$ and the IMMA score as predictors was calculated. The relative contributions to the model, which explained almost half of the observed anatomical variance $\left(R^{2}=\right.$ 0.42 ), were $\beta=0.83$ for the IMMA score versus $\beta=0.17$ for the $I_{\mathrm{MP}}$. This highlights the crucial importance of neuroanatomical dispositions for musical skills and suggests that musical training was not the cause of the observed interindividual variability in AC morphology.

\section{Primary auditory-evoked responses}

The volumetric predominance of HG in HPs and left PT in children with attention disorders was paralleled by corresponding functional findings. We performed MEG recordings in which the subjects were instructed to listen passively to the sounds of various musical instruments and artificial tones. The AC responses were modeled with one equivalent current dipole in each hemisphere (see Materials and Methods). As expected, responses were robustly localized in the right and left HG in the main group. However, for the $\mathrm{AD}(\mathrm{H}) \mathrm{D}$ children, the source was more posterior in the PT of the left hemisphere (Fig. 3A). Figure $3 B$ depicts the averaged time course of the auditory response (source waveform) at MTP2 for LPs, HPs, and $\mathrm{AD}(\mathrm{H}) \mathrm{D}$ children, respectively. Typically, a first positive response complex, referred to as the $\mathrm{P} 1$, arises $\sim 70-$ $100 \mathrm{~ms}$ after tone onset. The N1 response, which was not present in all children at this age because of a late maturation of this component, showed a typical peak latency of 200-270 ms after tone onset. Table 3 displays the P1 peak amplitudes and latencies of the right and left hemisphere at both MTPs. Furthermore, the latency reduction from MTP1 to MTP2 and bilateral P1 asynchrony are indicated.

There were significant group differences, with HPs exhibiting larger $\mathrm{P} 1$ amplitudes $\left(F_{(2,119)}=16.2 ; p=6 \times 10^{-7}\right.$; partial $\eta^{2}=$ $0.21)$ and shorter P1 latencies $\left(F_{(2,119)}=3.4 ; p=0.037\right.$; partial $\left.\eta^{2}=0.05\right)$ than LPs and $\mathrm{AD}(\mathrm{H}) \mathrm{D}$ children. This pattern was also reflected by a robust correlation between the right hemispheric $\mathrm{HG} / \mathrm{PT}$ ratio and $\mathrm{P} 1$ amplitude (main group only, $r=0.65, p=$ $3.6 \times 10^{-13}$; all children, Fig. $\left.4 E\right)$. There were significant corre- 
lations between the IMMA musicality score and P1 amplitude $\left(r=0.58, p=8.5 \times 10^{-10}\right)$ and latency $(r=-0.34, p=0.001)$, with the former effect being more pronounced for the right hemisphere (Fig. 4I).

$\mathrm{AD}(\mathrm{H}) \mathrm{D}$ children were characterized by an atypical lateralization pattern of accelerated right hemispheric $(81 \mathrm{~ms})$ and delayed left hemispheric responses $(101 \mathrm{~ms})$. This complements the atypical P1 source localizations observed in the $\mathrm{AD}(\mathrm{H}) \mathrm{D}$ group (Fig. 3A).

Moreover, there were significant main effects for hemisphere, with higher P1 amplitudes on the left side $\left(F_{(1,119)}=32.5 ; p=\right.$ $8.9 \times 10^{-8}$; partial $\left.\eta^{2}=0.21\right)$ and shorter P1 latencies on the right side $\left(F_{(1,119)}=120 ; p=9.8 \times 10^{-20}\right.$; partial $\left.\eta^{2}=0.5\right)$.

\section{Interhemispheric synchronization}

Bilateral asynchrony $\left(\mid \mathrm{P} 1_{\text {right }}-\right.$ left $\left.\mid\right)$ varied considerably among groups $\left(F_{(1,119)}=61.5 ; p=4.6 \times 10^{-19}\right.$; partial $\eta^{2}=0.51$; Fig. $3 B$; Table 3$)$. As evident from the superposition of the right- and left-hemispheric source waveforms, $\mathrm{AD}(\mathrm{H}) \mathrm{D}$ children showed a very high mean asynchrony of $22.5 \mathrm{~ms}$, approximately three times higher than in LPs $\left(7.1 \mathrm{~ms} ; p=1.1 \times 10^{-13}\right)$ and more than five times higher than in HPs $\left(4.2 \mathrm{~ms} ; p=3 \times 10^{-19}\right)$. Figure $4 G$ shows that bilateral asynchrony gradually increased with the DISYPS-based DCL-HKS index of $\mathrm{AD}(\mathrm{H}) \mathrm{D}$ symptom strength $\left(r=0.52, p=1 \times 10^{-9}\right)$.

Bilateral asynchrony decreased significantly with increasing $I_{\mathrm{MP}}$ (main group, $r=-0.27, p=0.006$ ), which provides evidence for a beneficial influence of musical practice on interhemispheric integration. Moreover, there was a negative correlation with the morphometric gray matter ratio HG/PT (main group, $r=-0.55$, $p=2.2 \times 10^{-7}$; all children, Fig. $4 D$ ), which means that a relative HG dominance was associated with bilaterally more synchronous $\mathrm{P} 1$ responses.

\section{Anatomical and functional maturation}

For gray matter volume, there was no significant difference between the two MTPs, and there were no interactions for MTP $\times$ hemisphere or MTP $\times$ group. Table 2 displays the mean volumes of $\mathrm{HG}, \mathrm{PT}$, and HG/PT ratio for the right and left hemisphere at both MTPs with significance values for the respective group and longitudinal comparisons. The individual gray matter volumes of AC were extremely stable over time. For $\mathrm{HG}$, the changes between the two MTPs were only $0.02 \%$ (Fig. $4 B$ ), resulting in a correlation of $r=0.98$ (Fig. 4C).

For the functional MEG data, the correlation of the amplitudes, latencies, and bilateral asynchronies of the P1 was very high between the two MTPs (amplitude, $r=0.79, p=4.9 \times$ $10^{-27}$; latency, $r=0.88, p=9 \times 10^{-40}$; asynchrony, $r=0.93$, $p=3 \times 10^{-53}$ ), albeit lower than for the HG and PT gray matter volumes. Hence, the source waveforms were highly reproducible as individual neurofunctional fingerprints. As expected from previous findings (Ponton et al., 2002), the P1 showed a mean latency reduction of $\sim 5 \mathrm{~ms}$ over the considered time interval of 13 months as a function of natural maturation (main effect of MTP, $F_{(1,119)}=113.2 ; p=5.5 \times 10^{-19}$; partial $\left.\eta^{2}=0.49\right)$. Moreover, there was a significant interaction for group $\times$ MTP $\left(F_{(2,119)}=9.5 ; p=1.4 \times 10^{-4}\right.$; partial $\left.\eta^{2}=0.14\right)$. The mean latency reduction was relatively small in $\mathrm{AD}(\mathrm{H}) \mathrm{D}$ children ( $3 \mathrm{~ms})$, somewhat higher in LPs ( $5 \mathrm{~ms})$, and highest in HPs ( $8 \mathrm{~ms}$; Table 3). This signifies a delayed maturation of AC in the $\mathrm{AD}(\mathrm{H}) \mathrm{D}$ group, which is contrasted by an exceptionally fast maturation in musically active children. Unlike P1 latency, P1 amplitude and bilateral asynchrony did not differ significantly between the two MTPs. Also, there were no hemispheric differences in the degree of $\mathrm{P} 1$ acceleration over time.

\section{Possible influences of gender}

To test the possibility that the unequal gender distributions in the three groups [all $\mathrm{AD}(\mathrm{H}) \mathrm{D}$ children were male] may have been responsible for some of the observed effects, the ANOVAs indicated in Tables 2 and 3 were repeated for boys only $[21 \mathrm{AD}(\mathrm{H}) \mathrm{D}$ children, 30 LPs, 24 HPs]. For the MRI-based analyses all main effects of group and for the MEG-based analyses, most main effects of group were still significant (see right columns of Tables 2 and 3). An inspection of the effect sizes (partial $\eta^{2}$ ), which unlike $p$ values do not depend on the sample size and may be compared across different analyses, indicates that these are similar for the mixed group and the male subgroup. This excludes the possibility that the effects seen in the original analyses are attributable to a gender bias.

\section{Neuroanatomical and functional markers of musicality and $\mathrm{AD}(\mathrm{H}) \mathrm{D}$}

To test how well different neurological parameters discriminate between LPs and HPs (first analysis) and children without developmental disorders and with $\mathrm{AD}(\mathrm{H}) \mathrm{D}$ (second analysis), we performed discriminant analyses that combined the four MRI-based predictors gray matter volumes of right and left HG and PT and the MEG-based predictor bilateral P1 asynchrony. In the first analysis, the established discriminant function allowed for a correct assignment of $78 \%$ of cases to the groups of LPs and HPs (Wilks' $\lambda=0.58, \chi^{2}=51.8, \mathrm{df}=5, p=5.8 \times 10^{-10}$ ). Gray matter volume of right HG was the most important segregating factor, with HPs showing substantially larger volumes than LPs. In the second analysis, the discriminant function correctly assigned $91 \%$ of cases to the groups of $\mathrm{AD}(\mathrm{H}) \mathrm{D}$ children and children without attention deficit disorder (Wilks' $\lambda=0.51, \chi^{2}=79$, $\left.\mathrm{df}=5, p=1 \times 10^{-13}\right)$. Bilateral asynchrony of the $\mathrm{P} 1$ response and enlarged gray matter volume of left PT (which is associated with a more posterior localization of the left P1 in PT; Fig. 3A) yielded the most important contributions to the auditory cortexrelated etiology of $\mathrm{AD}(\mathrm{H}) \mathrm{D}$.

\section{Auditory and cognitive skills}

Frequency discrimination was measured with the Dinosaur Test (Sutcliffe and Bishop, 2005; modified version: Huss et al., 2011). The children's frequency difference limens ranged from 0.05 to 1.9 semitones and correlated with $I_{\mathrm{MP}}(r=-0.35, p=4.7 \times$ $\left.10^{-5}\right)$, the IMMA musicality score $\left(r=-0.5, p=2.8 \times 10^{-7}\right)$, and $\mathrm{HG}$ gray matter volume, especially in the right hemisphere (right, $r=-0.34, p=-0.0001$; left, $r=-0.23, p=-0.009$ ). To clarify whether the morphology of right HG explains differences in pitch perception regardless of musical training, partial correlations were computed, in which the influence of $I_{\mathrm{MP}}$ was controlled. The correlation was still significant $(r=-0.22, p=$ 0.015). Conversely, when neuroanatomical dispositions (right and left HG volumes) were partialled out, the correlation remained significant as well $(r=-0.26, p=0.004)$. This shows that AC morphology and musical training both have an influence on the accuracy of auditory perception.

Intelligence, as measured with the CFIT [MTP1: CFT1 (Cattell et al., 1997); MTP2: CFT20-R (Weiß, 2008)], did not significantly differ between LPs, HPs, and $\mathrm{AD}(\mathrm{H}) \mathrm{D}$ children $\left(\mathrm{MTP} 1, F_{(2,128)}=0.48\right.$, n.s.; MTP2, $F_{(2,122)}=0.42$, n.s. $)$.

The children's literacy skills, which were measured by the German tests SLS (Mayringer and Wimmer, 2003) and HSP (May, 


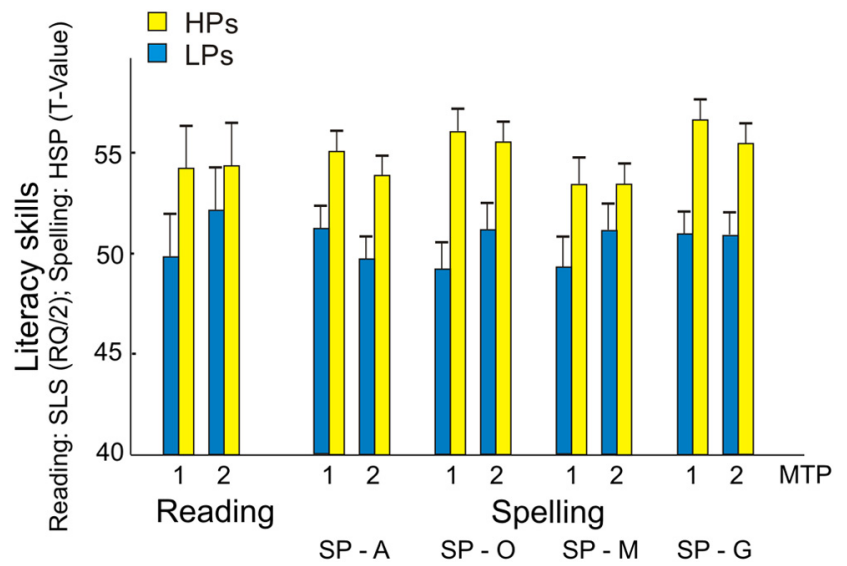

Figure 5. Reading and literacy skills. Differences between LPs (yellow) and HPs (blue) with regard to five indicators of literacy at the first (1) and second (2) MTP. A value of 50 corresponds to the mean of the age-related norm. Reading skills refer to the reading quotient (RQ/2) obtained by the German test SLS. Spelling skills refer to the $T$ values for three spelling strategies (SP-A, alphabetic;SP-0, orthographic; SP-M, morphematic) and the number of correctly spelled difficult word spots (SP-G, grapheme hits) for the German test HSP. Error bars indicate SEM.

2002), were related to musical activities. In the following, only the results of the main group are considered to avoid biasing by the poorer frequency discrimination scores, lower reading and spelling skills, and lower $I_{\mathrm{MP}}$ of the $\mathrm{AD}(\mathrm{H}) \mathrm{D}$ children. In principle, cognitive advantages related to musical training may be indirectly mediated by a more supportive social background. To consider this possibility, the individual scores on the three socioeconomic dimensions education environment, parental support, and resources and leisure activities were arithmetically eliminated in partial correlation analyses. At MTP1, four indicators of reading and spelling abilities were positively correlated with $I_{\mathrm{MP}}$ (reading quotient, $r=0.21, p=0.037$; orthographic strategy, $r=0.37, p=$ $1.8 \times 10^{-4}$; morphematic strategy, $r=0.27, p=0.01$; grapheme hits, $\left.r=0.33, p=8.6 \times 10^{-4}\right)$. At MTP2, there was a positive correlation for three indicators of literacy (orthographic strategy, $r=0.27, p=0.007$; morphematic strategy, $r=0.35, p=3.5 \times$ $10^{-4}$; grapheme hits, $r=0.37, p=1.8 \times 10^{-4}$; Bonferroni'sadjusted $\alpha$ level for multiple correlations, $p \leq 0.01$ ). The adjustment for socioeconomic status shows that the observed correlations between musical training and literacy were not an indirect consequence of social support. The corresponding group differences between LPs and HPs are indicated in Fig. 5; a value of 50 in the figure corresponds to the mean age-related norms of the literacy tests SLS and HSP. The performance of LPs was typical for their age, whereas HPs exceeded expectations on all indicators of literacy.

With regard to neuroanatomy, there were significant positive correlations between the gray matter volume of right HG and each of the five performance measures of reading and spelling $(p<0.05)$. To test whether the gross morphology of AC was causing differences in literacy skills, partial correlations were computed, in which the influence of musical training $\left(I_{\mathrm{MP}}\right)$ was eliminated. In this case, none of the correlations between the anatomical and literacy measures remained significant.

\section{Discussion}

In our study, structural MRI and functional MEG were applied to 132 elementary school children. There were remarkable individual and group-specific differences in gross morphological size, neural efficiency, and bilateral synchronization of AC. These combined anatomical and functional parameters turned out to be reliable neural markers of musicality, perceptual skills, and attention deficits. The longitudinal comparisons revealed a high stability of AC morphology but with systematic plastic changes at the functional level.

\section{Individual differences in the gross morphology of AC}

Children with musical training showed considerably larger HGsparticularly in the right hemisphere-than children without musical training. Conversely, $\mathrm{AD}(\mathrm{H}) \mathrm{D}$ children were characterized by exceptionally small HGs that were associated with enlarged PTs. Thus, the ratio HG/PT appears to be a key indicator of interindividual differences in AC morphology. However, the extent to which such differences are a result of experiencedependent, intrauterine, or genetic influences or a combination of these factors is a matter of debate in both cross-sectional (Golestani et al., 2011; Herholz and Zatorre, 2012; Ressel et al., 2012; Zatorre 2013; Oikkonen et al., 2014) and longitudinal (Hyde et al., 2009; Moreno et al., 2009; Besson et al., 2011; Penhune, 2011; Schellenberg, 2011; Chobert et al., 2014) studies. Prenatal investigations have shown that the HG is developed by week 31 of gestational age. In most cases, right HG develops 1 to 2 weeks earlier than the left (Chi et al., 1977). The morphology and asymmetry of the PT becomes visible at gestational week 30 and appears to remain fairly stable across fetuses, newborns, children, and adults (Preis et al., 1999). Studies with monozygotic and dizygotic twins have demonstrated that morphometric differences of AC are predominantly attributable to genetic factors; heritability is estimated at $80 \%$ for the left and $77 \%$ for right HG (Hulshoff Pol et al., 2006). The remaining variance may be accounted for by common environmental influences in utero and after birth and a combination of error and specific external influences not shared by the twins (Carmelli et al., 2002).

In our longitudinal study, the gray matter volume of relevant structures in AC was extremely stable over time, which suggests that the gross morphology of AC has primarily stabilized at the primary school age. Nevertheless, it is possible that other neuroanatomical parameters, such as cortical thickness or white matter connectivity, are still susceptible to auditory learning. The high interindividual variability in the size, shape, and lateralization of $\mathrm{HG}$ and PT observed in children (Fig. 2B) and adults (Schneider et al., 2002, 2005, 2009; Warrier et al., 2009) may be a result of a complex interaction between genetic factors and early auditory learning.

Furthermore, our data demonstrate that the gray matter volume, especially of the right HG, is directly related to both musical aptitude, as measured by the IMMA test (Gordon, 1986), and the intensity of musical practice at the outset of formal musical training. A regression analysis revealed that the right $\mathrm{HG} / \mathrm{PT}$ ratio was predominantly explained by the aptitude measure $(83 \%)$, whereas the practice measure played a subordinate role $(17 \%)$. Furthermore, the amount of musical practice between MTP1 and MTP2 significantly depended on AC morphology, even after controlling for the time invested in musical activities before the study. This suggests that a large right HG signifies high musical potential, which increases a child's intrinsic motivation to learn and practice a musical instrument regardless of social influences.

The size of right and left HG was also positively correlated with auditory and literacy skills, which is evidence for a close interdependency between AC morphology, perception, and cognition. According to partial correlations, accuracy of frequency discrimination was independently influenced by right HG volume and the extent of musical practice. Conversely, the exceptionally good performance in reading and spelling in HPs 


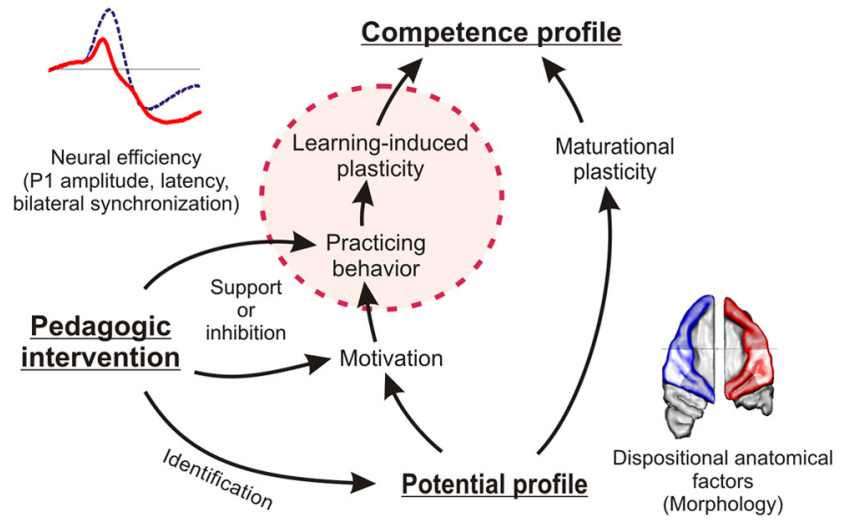

Figure 6. Neurocognitive model of competence development. The model describes the interaction between dispositional factors (potential profile, bottom), natural maturation (right vertical path), and training-induced plasticity (left vertical path). Pedagogic interventions (left) may affect learning-induced plasticity at different levels, thereby contributing to the manifestation of the individual competence profile (top). In the case of music processing, AC morphology (bottom right) and the source waveforms of the auditory-evoked fields (top left) represent dispositional and training-induced factors, respectively.

depended only on musical training, regardless of neuroanatomical dispositions and social background. This corroborates the existence of learning-induced transfer effects from the musical to the literacy domain and is consistent with previous longitudinal studies reporting positive musical transfer effects on general auditory skills (Banai and Ahissar, 2013; Putkinen et al., 2013), speech-related abilities (Ho et al., 2003; Magne et al., 2006; Forgeard et al., 2008; Moreno et al., 2009; Besson et al., 2011), and cognitive development (Trainor et al., 2009; Schellenberg, 2011; Corrigall et al., 2013).

At present, it is only possible to speculate why the gray matter volume of the left PT was substantially greater in $\mathrm{AD}(\mathrm{H}) \mathrm{D}$ children and why this measure was correlated to $\mathrm{AD}(\mathrm{H}) \mathrm{D}$-relevant behavior, as measured by the DCL-HKS score of the DISYPS (Doepfner and Lehmkuhl, 2000). Apart from genetic influences, a delay in the neural pruning process may be a factor (Castellanos et al., 2002). From birth to puberty, the overall number of cortical neurons and synapses decreases as a consequence of maturational and use-dependent plasticity (Iglesias et al., 2005). A disturbance of this process in the form of diminished or delayed pruning may result in oversized anatomical structures and functionally inefficient neural networks. Consistently, Sowell et al. (2003) reported that children and adults with $\mathrm{AD}(\mathrm{H}) \mathrm{D}$ have more gray matter in large portions of the posterior temporal cortices bilaterally, which is associated with a reduced myelination and white matter connectivity in these regions.

\section{Individual differences and plastic changes in the neural efficiency of AC}

We found that the primary auditory-evoked responses of musically active children have a significantly higher amplitude, shorter latency (at least on the left side), and higher bilateral synchrony, which suggests enhanced neural efficiency of the underlying networks; this may either be attributable to a larger number of neurons or increased synchronization (Eggermont and Ponton, 2002). As expected (Ponton et al., 2002), the longitudinal comparison revealed maturational plasticity in all children, leading to decreasing P1 peak latencies with age. Short latencies signify a high degree of myelination of the transmitting nerve fibers and indicate a mature developmental state (Roberts et al., 2009). Our findings show that this natural development was accelerated in children with regular musical practice.

The size ratio of HG/PT and the bilateral asynchrony of the P1 response differentiated children with respect not only to musicality but also to the incidence of attention disorders. $\mathrm{AD}(\mathrm{H}) \mathrm{D}$ children showed an atypical volumetric predominance of PT over HG, especially on the left side, and an intriguing bilateral asynchrony of the P1 that was more than five times higher than in the musically experienced group. Moreover, the left P1 response was characterized by delayed latencies and a posteriorly shifted source location. This suggests that supratemporal lobe functions are crucially involved in attention deficits, complementing the influence of executive functions located in parietofrontal cortical networks (Sergeant et al., 2003; Larsson et al., 2006; Konrad and Eickhoff, 2010). We assume that the oversized and probably inefficient left PT, together with diminished white matter connectivity in the posterior temporal regions (Sowell et al., 2003), can explain the observed functional anomalies in our $\mathrm{AD}(\mathrm{H}) \mathrm{D}$ sample.

Poeppel (2003) proposed an asymmetric sampling in time (AST) model, which was later refined by Meyer et al. (2012). The model is based on the observation that the auditory association cortex is asymmetrically driven by temporal modulations in acoustic signals. While the left AC is basically involved in decoding rapidly changing acoustic segments $(\sim 40 \mathrm{~Hz})$, the right $\mathrm{AC}$ supports the processing of suprasegmental, slowly changing acoustic cues $(\sim 4 \mathrm{~Hz})$. The model postulates that the left hemispheric analysis of fine-grained acoustic information, which is important for the phonetic discrimination of voice onset times in speech (stop consonants b-p, d-t, g-k) and onset-based instrumental timbres in music, is a prerequisite for the subsequent slow right hemispheric pattern analysis of prosodic and rhythmic information. Consistently, the left PT is involved in the analysis of voice-onset times (Jäncke et al., 2002), whereas the right PT supports the processing of speech melody (Meyer et al., 2004) and speech rhythm (Geiser et al., 2008). Hence, a developmental deficit in the left PT would cause problems not only in the initial fast analysis but also in the subsequent slow analysis of the contralateral hemisphere, leading to difficulties in discriminating the onsets of syllables and perceiving rhythmic structures in speech and music. Both types of deficits are characteristic for children with CAPD and dyslexia (Hämäläinen et al., 2013; Leong and Goswami, 2014), which are frequently associated with $\mathrm{AD}(\mathrm{H}) \mathrm{D}$ (Sergeant et al., 2003). Recent studies have confirmed the significance of the AST model for dyslexia (Goswami, 2011; Lehongre et al., 2011; Kraus, 2012). It might be promising to test the validity of this approach for CAPD and $\mathrm{AD}(\mathrm{H}) \mathrm{D}$. In particular, the model might account for the growing body of evidence that, beyond well known deficits in executive functions (Konrad and Eickhoff, 2010), auditory timing deficits are associated with $\mathrm{AD}(\mathrm{H}) \mathrm{D}$ (Falter and Noreika, 2011; Noreika et al., 2013). The strong interdependence between auditory and attentional functions is evidenced by the multimodal organization of AC with wide feedback loops to subcortical and prefrontal regions that also comprise attentional networks (Scheich et al., 2011). The striking bilateral asynchrony measured in our $\mathrm{AD}(\mathrm{H}) \mathrm{D}$ sample may reflect a disturbed division of labor in temporal signal analysis between left and right AC that originates from a developmental anomaly of the left PT and has negative consequences for attentional, linguistic, and literacy skills. Our findings suggest that the high correlation between CAPD and AD (H)D (Riccio et al., 1994, 2005) signifies common deficits in primary auditory processing 
(Chermak et al., 1999) rather than in attentional top-down processing (Sagvolden et al., 2005).

Our data also indicate that musical training has the capacity to synchronize the activation of left and right AC and thereby to increase interhemispheric transfer. The inverse neurofunctional patterns seen in musically experienced and $\mathrm{AD}(\mathrm{H}) \mathrm{D}$ children suggest that musical activities may be beneficial not only for auditory (Kraus and Chandrasekaran, 2010) but also for attentional, linguistic, and literacy skills (Golestani et al., 2007; Wong et al., 2008; Hartwigsen et al., 2010). In particular, playing an instrument may counteract developmental delays by accelerating the functional maturation of $\mathrm{AC}$ and enhancing the synchronization of left and right hemisphere functions, for example, through intensified white matter connectivity (Zatorre et al., 2012). By combining the structural characteristics with the functional $\mathrm{P} 1$ asynchrony, it was possible to predict $\mathrm{AD}(\mathrm{H}) \mathrm{D}$ (as diagnosed by pediatricians and/or psychologists) with $\sim 90 \%$ accuracy. Thus, our experimental approach may also be of clinical relevance.

\section{Neurocognitive model for musical potential and competence} In general, our findings suggest that the gross morphology of AC has primarily stabilized at an age when intensive formal musical education normally starts. The high morphological variability between subjects may instead be attributed to early informal musical experiences, general auditory learning, intrauterine learning, or genetic influences. The gray matter volume of right HG appears to have a considerable influence on a child's motivation to learn and practice a musical instrument. This training, in turn, seems to intensify the neural efficiency of AC (enhanced and accelerated P1 responses with a high bilateral synchrony). Therefore, the influences of musical aptitude and musical training should not be seen as mutually exclusive but rather as mutually reinforcing. On this basis, we propose an extended neurocognitive model that describes development from a set of dispositional factors, specified as a potential profile, to a competence profile that represents the neurocognitive state accomplished so far (Fig. 6). There are two main paths that affect the speed and quality of development. On one hand, biological factors, such as genes, hormones, and transmitters, promote maturational plasticity with age and enable the development of perceptual and cognitive skills (Fig. 6, right path). On the other hand, advantageous predispositions (in the case of music, a large right $\mathrm{HG}$ ) are likely to increase motivation to practice. This, in turn, may lead to training-induced neural plasticity (left path) and enhanced neural efficiency (in the case of music, boosted, accelerated, and highly synchronized P1 responses to auditory stimuli). Most studies on auditory plasticity have focused on the practice aspect (Fig. 6, red dashed circle) and have demonstrated considerable learning-induced changes (for review, see Strait and Kraus, 2014). Our data suggest that it may be also important to consider a child's latent potentials and intrinsic motivations (left side of the figure), because early identification, support, and pedagogic interventions are likely to promote brain development.

\section{References}

Altenmüller E (2008) Neurology of musical performance. Clin Med 8:410413. CrossRef Medline

Bailey T (2012) Beyond DSM: the role of auditory processing in attention and its disorders. Appl Neuropsychol Child 1:112-120. CrossRef Medline

Banai K, Ahissar M (2013) Musical experience, auditory perception and reading-related skills in children. PLoS One 8:e75876. CrossRef Medline

Besson M, Faita F (1995) An event-related potential (ERP) study of musical expectancy: comparison of musicians with nonmusicians. J Exp Psychol Human Percept Perform 21:1278-1296. CrossRef

Besson M, Chobert J, Marie C (2011) Transfer of training between music and speech: common processing, attention, and memory. Front Psychol 2:94. CrossRef Medline

Cacace AT, McFarland DJ (1998) Central auditory processing disorder in school-aged children: a critical review. J Speech Lang Hear Res 41:355373. CrossRef Medline

Carmelli D, Swan GE, DeCarli C, Reed T (2002) Quantitative genetic modeling of regional brain volumes and cognitive performance in older male twins. Biol Psychol 61:139-155. CrossRef Medline

Castellanos FX, Lee PP, Sharp W, Jeffries NO, Greenstein DK, Clasen LS, Blumenthal JD, James RS, Ebens CL, Walter JM, Zijdenbos A, Evans AC, Giedd JN, Rapoport JL (2002) Developmental trajectories of brain volume abnormalities in children and adolescents with attention-deficit/ hyperactivity disorder. JAMA 288:1740-1748. CrossRef Medline

Cattell RB, Weiß RH, Osterland J (1997) Grundintelligenztest Skala 1 (CFT1). Goettingen, Germany: Hogrefe.

Chen JL, Penhune VB, Zatorre RJ (2008) Moving on time: Brain network for auditory-motor synchronization is modulated by rhythm complexity and musical training. J Cogn Neurosci 20:226-239. CrossRef Medline

Chermak GD, Hall JW 3rd, Musiek FE (1999) Differential diagnosis and management of central auditory processing disorder and attention deficit hyperactivity disorder. J Am Acad Audiol 10:289-303. Medline

Chermak GD, Musiek FE (1997) Central auditory processing disorders: new perspectives. San Diego: Singular Publishing Group.

Chi JG, Dooling EC, Gilles FH (1977) Gyral development of the human brain. Ann Neurol 1:86-93. CrossRef Medline

Chobert J, François C, Velay JL, Besson M (2014) Twelve months of active musical training in 8- to 10-year-old children enhances the preattentive processing of syllabic duration and voice onset time. Cereb Cortex 24: 956-967. CrossRef Medline

Corrigall KA, Schellenberg EG, Misura NM (2013) Music training, cognition, and personality. Front Psychol 4:222. CrossRef Medline

Da Costa S, van der Zwaag W, Miller LM, Clarke S, Saenz M (2013) Tuning in to sound: frequency-selective attentional filter in human primary auditory cortex. J Neurosci 33:1858-1863. CrossRef Medline

Dawes P, Sirimanna T, Burton M, Vanniasegaram I, Tweedy F, Bishop DV (2009) Temporal auditory and visual motion processing of children diagnosed with auditory processing disorder and dyslexia. Ear Hear 30:675686. CrossRef Medline

Doepfner M, Lehmkuhl G (2000) Diagnostik-System für psychische Stoerungen im Kindes und Jugendalter nach ICD10 und DSM IV (DISYPS KJ), Ed 2. Bern, Switzerland: Verlag Hans Huber.

Eggermont JJ, Ponton CW (2002) The neurophysiology of auditory perception: from single units to evoked potentials. Audiol Neurootol 7:71-99. CrossRef Medline

Falter CM, Noreika V (2011) Interval timing deficits and abnormal cognitive development. Front Integr Neurosci 5:26. CrossRef Medline

Forgeard M, Winner E, Norton A, Schlaug G (2008) Practicing a musical instrument in childhood is associated with enhanced verbal ability and nonverbal reasoning. PLoS One 3:e3566. CrossRef Medline

Foster NE, Zatorre RJ (2010) Cortical structure predicts success in performing musical transformation judgments. Neuroimage 53:26-36. CrossRef Medline

Fujioka T, Ross B, Kakigi R, Pantev C, Trainor LJ (2006) One year of musical training affects development of auditory cortical-evoked fields in young children. Brain 129:2593-2608. CrossRef Medline

Geiser E, Zaehle T, Jancke L, Meyer M (2008) The neural correlate of speech rhythm as evidenced by metrical speech processing. J Cogn Neurosci 20:541-552. CrossRef Medline

Golestani N, Molko N, Dehaene S, LeBihan D, Pallier C (2007) Brain structure predicts the learning of foreign speech sounds. Cereb Cortex 17:575582. CrossRef Medline

Golestani N, Price CJ, Scott SK (2011) Born with an ear for dialects? structural plasticity in the expert phonetician brain. J Neurosci 31:4213-4220. CrossRef Medline

Gordon E (1986) Intermediate measures of music audiation. Chicago: GIA Publications.

Goswami U (2011) A temporal sampling framework for developmental dyslexia. Trends Cogn Sci 15:3-10. CrossRef Medline

Grau-Sánchez J, Amengual JL, Rojo N, Veciana de Las Heras M, Montero J, 
Rubio F, Altenmüller E, Münte TF, Rodríguez-Fornells A (2013) Plasticity in the sensorimotor cortex induced by music-supported therapy in stroke patients: a TMS study. Front Hum Neurosci 7:494. CrossRef Medline

Hämäläinen JA, Salminen HK, Leppänen PHT (2013) Basic auditory processing deficits in dyslexia: Systematic review of the behavioral and eventrelated potential/field evidence. J Learn Disabil 46:413-427. CrossRef Medline

Hartwigsen G, Baumgaertner A, Price CJ, Koehnke M, Ulmer S, Siebner HR (2010) Phonological decisions require both the left and right supramarginal gyri. Proc Natl Acad Sci U S A 107:16494-16499. CrossRef Medline

Herdener M, Esposito F, Scheffler K, Schneider P, Logothetis NK, Uludag K, Kayser C (2013) Spatial representations of temporal and spectral sound cues in human auditory cortex. Cortex 49:2822-2833. CrossRef Medline

Herholz SC, Zatorre RJ (2012) Musical training as a framework for brain plasticity: behavior, function, and structure. Neuron 76:486-502. CrossRef Medline

Ho YC, Cheung MC, Chan AS (2003) Music training improves verbal but not visual memory: cross-sectional and longitudinal explorations in children. Neuropsychology 17:439-450. CrossRef Medline

Hulshoff Pol HE, Schnack HG, Posthuma D, Mandl RCW, Baaré WF, van Oel C, van Haren NE, Collins DL, Evans AC, Amunts K, Bürgel U, Zilles K, de Geus E, Boomsma DI, Kahn RS (2006) Genetic contributions to human brain morphology and intelligence. J Neurosci 26:10235-10242. CrossRef Medline

Huss M, Verney JP, Fosker T, Mead N, Goswami U (2011) Music, rhythm, rise time perception and developmental dyslexia: Perception of musical meter predicts reading and phonology. Cortex 47:674-689. CrossRef Medline

Hyde KL, Lerch J, Norton A, Forgeard M, Winner E, Evans AC, Schlaug G (2009) Musical training shapes structural brain development. J Neurosci 29:3019-3025. CrossRef Medline

Iglesias J, Eriksson J, Grize F, Tomassini M, Villa AE (2005) Dynamics of pruning in simulated large-scale spiking neural networks. BioSystems 79:11-20. CrossRef Medline

Jäncke L (2009) The plastic human brain. Restor Neurol Neurosci 27:521538. CrossRef Medline

Jäncke L, Loose R, Lutz K, Specht K, Shah NJ (2000) Cortical activations during paced finger-tapping applying visual and auditory pacing stimuli. Brain Res Cogn Brain Res 10:51-66. CrossRef Medline

Jäncke L, Wüstenberg T, Scheich H, Heinze HJ (2002) Phonetic perception and the temporal cortex. Neuroimage 15:733-746. CrossRef Medline

Janata P (2012) Effects of widespread and frequent personalized music programming on agitation and depression in assisted living facility residents with alzheimer-type dementia. Music Med 4:8-15. CrossRef

Koelsch S, Schröger E, Tervaniemi M (1999) Superior pre-attentive auditory processing in musicians. Neuroreport 10:1309-1313. CrossRef Medline

Koelsch S, Schmidt BH, Kansok J (2002) Effects of musical expertise on the early right anterior negativity: an event-related brain potential study. Psychophysiology 39:657-663. CrossRef Medline

Koelsch S, Fritz T, Schulze K, Alsop D, Schlaug G (2005) Adults and children processing music: an fMRI study. Neuroimage 25:1068-1076. CrossRef Medline

Konrad K, Eickhoff SB (2010) Is the ADHD brain wired differently? A review on structural and functional connectivity in attention deficit hyperactivity disorder. Hum Brain Mapp 31:904-916. CrossRef Medline

Kraus N (2012) Atypical brain oscillations: A biological basis for dyslexia? Trends Cogn Sci 16:12-13. CrossRef Medline

Kraus N, Chandrasekaran B (2010) Music training for the development of auditory skills. Nat Rev Neurosci 11:599-605. CrossRef Medline

Larsson H, Lichtenstein P, Larsson JO (2006) Genetic contributions to the development of ADHD subtypes from childhood to adolescence. J Am Acad Child Adolesc Psych 45:973-981. CrossRef Medline

Lehongre K, Ramus F, Villiermet N, Schwartz D, Giraud AL (2011) Altered low-gamma sampling in auditory cortex accounts for the three main facets of dyslexia. Neuron 72:1080-1090. CrossRef Medline

Leonard CM, Puranik C, Kuldau JM, Lombardino LJ (1998) Normal variation in the frequency and location of human auditory cortex landmarks. Heschl's gyrus: where is it? Cereb Cortex 8:397-406. CrossRef Medline

Leong V, Goswami U (2014) Impaired extraction of speech rhythm from temporal modulation patterns in speech in developmental dyslexia. Front Hum Neurosci 8:96. CrossRef Medline

Magne C, Schön D, Besson M (2006) Musician children detect pitch viola- tions in both music and language better than nonmusician children: behavioral and electrophysiological approaches. J Cogn Neurosci 18:199_ 211. CrossRef Medline

Marie D, Jobard G, Crivello F, Perchey G, Petit L, Mellet E, Joliot M, Zago L, Mazoyer B, Tzourio-Mazoyer N (2013) Descriptive anatomy of Heschl's gyri in 430 healthy volunteers, including 198 left-handers. Brain Struct Funct. Advance online publication. Retrieved July 5, 2014. doi: 10.1007/s00429-013-0680-x. CrossRef Medline

Martel MM, Klump K, Nigg JT, Breedlove SM, Sisk CL (2009) Potential hormonal mechanisms of attention-deficit/hyperactivity disorder and major depressive disorder: a new perspective. Horm Behav 55:465-479. CrossRef Medline

May P (2002) Hamburger Schreib-Probe 1-9. Hamburg: Verlag fuer Paedagogische Medien.

Mayringer H, Wimmer H (2003) Salzburger Lese-Screening fuer die Klassenstufen 1-4 (SLS 1-4). Bern, Switzerland: Hogrefe.

Meyer M, Steinhauer K, Alter K, Friederici AD, von Cramon DY (2004) Brain activity varies with modulation of dynamic pitch variance in sentence melody. Brain Lang 89:277-289. CrossRef Medline

Meyer M, Elmer S, Jäncke L (2012) Musical expertise induces neuroplasticity of the planum temporale. Ann N Y Acad Sci 1252:116-123. CrossRef Medline

Micheyl C, Delhommeau K, Perrot X, Oxenham AJ (2006) Influence of musical and psychoacoustical training on pitch discrimination. Hear Res 219:36-47. CrossRef Medline

Moreno S, Marques C, Santos A, Santos M, Castro SL, Besson M (2009) Musical training influences linguistic abilities in 8-year-old children: More evidence for brain plasticity. Cereb Cortex 19:712-723. CrossRef Medline

Münte TF, Altenmüller E, Jäncke L (2002) The musician's brain as a model of neuroplasticity. Nat Rev Neurosci 3:473-478. CrossRef Medline

Nombela C, Hughes LE, Owen AM, Grahn JA (2013) Into the groove: can rhythm influence parkinson's disease? Neurosci Biobehav Rev 37:25642570. CrossRef Medline

Noreika V, Falter CM, Rubia K (2013) Timing deficits in attention-deficit/ hyperactivity disorder (ADHD): evidence from neurocognitive and neuroimaging studies. Neuropsychologia 51:235-266. CrossRef Medline

Oikkonen J, Huang Y, Onkamo P, Ukkola-Vuoti L, Raijas P, Karma K, Vieland VJ, Jarvela I (2014) A genome-wide linkage and association study of musical aptitude identifies loci containing genes related to inner ear development and neurocognitive functions. Mol Psychiatry. Advance online publication. Retrieved July 5, 2014. doi:10.1038/mp.2014.8. CrossRef Medline

Pantev C, Oostenveld R, Engelien A, Ross B, Roberts LE, Hoke M (1998) Increased auditory cortical representation in musicians. Nature 392:811814. CrossRef Medline

Pantev C, Roberts LE, Schulz M, Engelien A, Ross B (2001) Timbre-specific enhancement of auditory cortical representations in musicians. Neuroreport 12:169-174. CrossRef Medline

Penhune VB (2011) Sensitive periods in human development: evidence from musical training. Cortex 47:1126-1137. CrossRef Medline

Penhune VB, Zatorre RJ, MacDonald JD, Evans AC (1996) Interhemispheric anatomical differences in human primary auditory cortex: probabilistic mapping and volume measurement for magnetic resonance scans. Cereb Cortex 6:661-672. CrossRef Medline

Penhune VB, Cismaru R, Dorsaint-Pierre R, Petitto LA, Zatorre RJ (2003) The morphometry of auditory cortex in the congenitally deaf measured using MRI. Neuroimage 20:1215-1225. CrossRef Medline

Poeppel D (2003) The analysis of speech in different temporal integration windows: cerebral lateralization as "asymmetric sampling in time." Speech Commun 41:245-255. CrossRef

Ponton C, Eggermont JJ, Khosla D, Kwong B, Don M (2002) Maturation of human central auditory system activity: separating auditory evoked potentials by dipole source modeling. Clin Neurophysiol 113:407-420. CrossRef Medline

Preis S, Jancke L, Schmitz-Hillebrecht J, Steinmetz H (1999) Child age and planum temporale asymmetry. Brain Cogn 40:441-452. CrossRef Medline

Putkinen V, Saarikivi K, Tervaniemi M (2013) Do informal musical activities shape auditory skill development in preschool-age children? Front Psychol 4:572. CrossRef Medline

Rademacher J, Caviness VS Jr, Steinmetz H, Galaburda AM (1993) Topographical variation of the human primary cortices: implications for neu- 
roimaging, brain mapping, and neurobiology. Cereb Cortex 3:313-329. CrossRef Medline

Rademacher J, Morosan P, Schormann T, Schleicher A, Werner C, Freund HJ, Zilles K (2001) Probabilistic mapping and volume measurement of human primary auditory cortex. Neuroimage 13:669-683. CrossRef Medline

Rammsayer T, Altenmueller E (2006) Temporal information processing in musicians and nonmusicians. Music Perception 24:37-48. CrossRef

Reifinger J (2006) Skill development in rhythm perception and performance: a review of literature. Update Appl Res Music Educ 25:15-27. CrossRef

Ressel V, Pallier C, Ventura-Campos N, Díaz B, Roessler A, Ávila C, Sebastián-Gallés N (2012) An effect of bilingualism on the auditory cortex. J Neurosci 32:16597-16601. CrossRef Medline

Riccio CA, Hynd GW, Cohen MJ, Hall J, Molt L (1994) Comorbidity of central auditory processing disorder and attention-deficit hyperactivity disorder. J Am Acad Child Adolesc Psychiatry 33:849-857. CrossRef Medline

Riccio CA, Cohen MJ, Garrison T, Smith B (2005) Auditory processing measures: correlation with neuropsychological measures of attention, memory, and behavior. Child Neuropsychol 11:363-372. CrossRef Medline

Roberts TP, Khan SY, Blaskey L, Dell J, Levy SE, Zarnow DM, Edgar JC (2009) Developmental correlation of diffusion anisotropy with auditoryevoked response. Neuroreport 20:1586-1591. CrossRef Medline

Sagvolden T, Johansen EB, Aase H, Russell VA (2005) A dynamic developmental theory of attention-deficit/hyperactivity disorder (ADHD) predominantly hyperactive/impulsive and combined subtypes. Behav Brain Sci 28:397-419; discussion 419-68. CrossRef Medline

Schadow J, Lenz D, Dettler N, Fründ I, Herrmann CS (2009) Early gammaband responses reflect anticipatory top-down modulation in the auditory cortex. Neuroimage 47:651-658. CrossRef Medline

Scheich H, Brechmann A, Brosch M, Budinger E, Ohl FW, Selezneva E, Stark H, Tischmeyer W, Wetzel W (2011) Behavioral semantics of learning and crossmodal processing in auditory cortex: the semantic processor concept. Hear Res 271:3-15. CrossRef Medline

Schellenberg EG (2011) Music lessons, emotional intelligence, and IQ. Music Perception 29:185-194. CrossRef

Schlaug G, Jäncke L, Huang Y, Steinmetz H (1995) In vivo evidence of structural brain asymmetry in musicians. Science 267:699-701. CrossRef Medline

Schneider P, Scherg M, Dosch HG, Specht HJ, Gutschalk A, Rupp A (2002) Morphology of Heschl's gyrus reflects enhanced activation in the auditory cortex of musicians. Nat Neurosci 5:688-694. CrossRef Medline

Schneider P, Sluming V, Roberts N, Scherg M, Goebel R, Specht HJ, Dosch HG, Bleeck S, Stippich C, Rupp A (2005) Structural and functional asymmetry of lateral Heschl's gyrus reflects pitch perception preference. Nat Neurosci 8:1241-1247. CrossRef Medline

Schneider P, Andermann M, Wengenroth M, Goebel R, Flor H, Rupp A, Diesch E (2009) Reduced volume of Heschl's gyrus in tinnitus. Neuroimage 45:927-939. CrossRef Medline

Schneider S, Schönle PW, Altenmüller E, Münte TF (2007) Using musical instruments to improve motor skill recovery following a stroke. J Neurol 254:1339-1346. CrossRef Medline

Seither-Preisler A, Johnson L, Krumbholz K, Nobbe A, Patterson R, Seither S, Lütkenhöner B (2007) Tone sequences with conflicting fundamental pitch and timbre changes are heard differently by musicians and nonmusicians. J Exp Psychol Hum Percept Perform 33:743-751. CrossRef Medline

Sergeant JA, Geurts H, Huijbregts S, Scheres A, Oosterlaan J (2003) The top and the bottom of ADHD: a neuropsychological perspective. Neurosci Biobehav Rev 27:583-592. CrossRef Medline

Shahin AJ, Roberts LE, Chau W, Trainor LJ, Miller LM (2008) Music training leads to the development of timbre-specific gamma band activity. Neuroimage 41:113-122. CrossRef Medline

Shaw P, Eckstrand K, Sharp W, Blumenthal J, Lerch JP, Greenstein D, Clasen L, Evans A, Giedd J, Rapoport JL (2007) Attention-deficit/hyperactivity disorder is characterized by a delay in cortical maturation. Proc Natl Acad Sci U S A 104:19649-19654. CrossRef Medline
Skoe E, Kraus N (2012) A little goes a long way: how the adult brain is shaped by musical training in childhood. J Neurosci 32:11507-11510. CrossRef Medline

Slater J, Tierney A, Kraus N (2013) At-risk elementary school children with one year of classroom music instruction are better at keeping a beat. PLoS One 8: e77250. CrossRef Medline

Sluming V, Brooks J, Howard M, Downes JJ, Roberts N (2007) Broca's area supports enhanced visuospatial cognition in orchestral musicians. J Neurosci 27:3799-3806. CrossRef Medline

Sowell ER, Thompson PM, Welcome SE, Henkenius AL, Toga AW, Peterson BS (2003) Cortical abnormalities in children and adolescents with attention-deficit hyperactivity disorder. Lancet 362:1699-1707. CrossRef Medline

Steinmetz H, Rademacher J, Huang YX, Hefter H, Zilles K, Thron A, Freund HJ (1989) Cerebral asymmetry: MR planimetry of the human planum temporale. J Comput Assist Tomogr 13:996-1005. CrossRef Medline

Strait DL, Kraus N (2014) Biological impact of auditory expertise across the life span: musicians as a model of auditory learning. Hear Res 308:109_ 121. CrossRef Medline

Sutcliffe P, Bishop D (2005) Psychophysical design influences frequency discrimination performance in young children. J Exp Child Psychol 91:249_ 270. CrossRef Medline

Tervaniemi M, Castaneda A, Knoll M, Uther M (2006) Sound processing in amateur musicians and nonmusicians: event-related potential and behavioral indices. Neuroreport 17:1225-1228. CrossRef Medline

Trainor LJ, Desjardins RN, Rockel C (1999) A comparison of contour and interval processing in musicians and nonmusicians using event-related potentials. Austr J Psychol 51:147-153. CrossRef

Trainor LJ, Shahin AJ, Roberts LE (2009) Understanding the benefits of musical training: effects on oscillatory brain activity Ann N Y Acad Sci 1169:133-142. CrossRef

Wan CY, Schlaug G (2010) Music making as a tool for promoting brain plasticity across the life span. Neuroscientist 16:566-577. CrossRef Medline

Warrier C, Wong P, Penhune V, Zatorre R, Parrish T, Abrams D, Kraus N (2009) Relating structure to function: Heschl's gyrus and acoustic processing. J Neurosci 29:61-69. CrossRef Medline

Weiß RH (2008) Grundintelligenztest Skala 2-Revision (CFT 20-R). Goettingen, Germany: Hogrefe.

Wengenroth M, Blatow M, Bendszus M, Schneider P (2010) Leftward lateralization of auditory cortex underlies holistic sound perception in Williams syndrome. PLoS One 5:e12326. CrossRef Medline

Wengenroth M, Blatow M, Heinecke A, Reinhardt J, Stippich C, Hofmann E, Schneider P (2014) Increased volume and function of right auditory cortex as a marker for absolute pitch. Cereb Cortex 24:1127-1137. CrossRef Medline

White-Schwoch T, Carr KW, Anderson S, Strait DL, Kraus N (2013) Older adults benefit from music training early in life: biological evidence for long-term training-driven plasticity. J Neurosci 33:17667-17674. CrossRef Medline

Wong PC, Warrier CM, Penhune VB, Roy AK, Sadehh A, Parrish TB, Zatorre RJ (2008) Volume of left Heschl's gyrus and linguistic pitch learning. Cereb Cortex 18:828-836. CrossRef Medline

Woods SP, Lovejoy DW, Ball JD (2002) Neuropsychological characteristics of adults with ADHD: a comprehensive review of initial studies. Clin Neuropsychol 16:12-34. CrossRef Medline

Zatorre R, McGill J (2005) Music, the food of neuroscience? Nature 434: 312-315. CrossRef Medline

Zatorre RJ (2013) Predispositions and plasticity in music and speech learning: neural correlates and implications. Science 342:585-589. CrossRef Medline

Zatorre RJ, Chen JL, Penhune VB (2007) When the brain plays music: auditory-motor interactions in music perception and production. Nat Rev Neurosci 8:547-558. CrossRef Medline

Zatorre RJ, Fields RD, Johansen-Berg H (2012) Plasticity in gray and white: neuroimaging changes in brain structure during learning. Nat Neurosci 15:528-536. CrossRef Medline 